\title{
Orientation Selectivity in Rabbit Retinal Ganglion Cells Is Mediated by Presynaptic Inhibition
}

\author{
Sowmya Venkataramani and W. Rowland Taylor \\ Casey Eye Institute, Department of Ophthalmology, Oregon Health \& Science University, Portland, Oregon 97239
}

Cells sensitive to the orientation of edges are ubiquitous in visual systems, and have been described in the vertebrate retina, yet the synaptic mechanisms that generate orientation selectivity in the retina are largely unknown. Here, we analyze the synaptic mechanisms that generate selective responses to vertically and horizontally oriented stimuli in rabbit retinal ganglion cells. The data indicate that the excitatory and inhibitory inputs to orientation-selective ganglion cells are rendered orientation selective within the presynaptic circuitry. In accordance with previous extracellular recordings, presynaptic GABAergic inhibition is critical to generate orientation selectivity, and we show that it includes lateral inhibition of glutamatergic bipolar cells and serial inhibitory connections between GABAergic and glycinergic amacrine cells. Despite very similar spiking properties, vertically and horizontally selective ganglion cells (VS-GCs and HS-GCs, respectively) show marked differences in their underlying synaptic mechanisms. Both cell types receive glutamatergic inputs via non-NMDA (AMPA/kainate) and NMDA receptors, while VS-GCs receive additional excitation mediated by glycinergic disinhibition. A striking difference between these cells is that during nonpreferred simulation, excitation is suppressed and direct glycinergic inhibition is increased in HS-GCs, whereas for VS-GCs, both excitatory and inhibitory inputs are suppressed. Thus, orientation selectivity is generated presynaptically both by modulation of bipolar cell output and by serial inhibitory connections between amacrine cells. Minimal circuit models are proposed that account for these observations.

\section{Introduction}

Orientation of an elongated object is a "trigger feature" commonly encountered in the visual system from retina to cortex. Cortical orientation selectivity (OS) was first discovered by Hubel and Wiesel (1962), who proposed that orientation selectivity of simple cells in the visual cortex could be explained by a simple feedforward model based on the spatial organization of the excitatory inputs from the lateral geniculate nucleus (Ferster and Miller, 2000). The center-surround receptive fields of the lateral geniculate neurons are arranged in rows, and hence a stimulus with the preferred orientation simultaneously activates more relay cells than a nonpreferred stimulus. The feedback model, which is equally compelling, proposes that orientation selectivity arises from extensive intracortical interactions and not just due to the spatial organization of the thalamic inputs to the simple cells of the cortex. While the feedforward model (Tanaka, 1983; Chapman et al., 1991; Reid and Alonso, 1995; Ferster and Miller, 2000; Wilent and Contreras, 2005; Bruno and Sakmann, 2006; Priebe and Ferster, 2008) relies solely on excitatory connections, inhibition is the key mechanism in the feedback model (Bishop et al., 1971; Sillito et al., 1980; Morrone et al., 1982;

Received April 22, 2010; revised Sept. 17, 2010; accepted Sept. 21, 2010.

This research was supported by National Eye Institute Grant EY014888. We thank Jacqueline Gayet for excellent technical support and assistance with rabbit dissection and immunology experiments. We also thank llya Buldyrev, Theresa Puthussery, Ben Sivyer, and David Vaney for helpful discussions and critical reading of this manuscript.

Correspondence should be addressed to Sowmya Venkataramani at the above address. E-mail: venkatas@ohsu.edu.

DOI:10.1523/JNEUROSCI.2081-10.2010

Copyright $\odot 2010$ the authors $\quad 0270-6474 / 10 / 3015664-13 \$ 15.00 / 0$
Vidyasagar and Heide, 1984; Binzegger et al., 2004; Stepanyants et al., 2008). Despite extensive data supporting both these models, the precise mechanism that generates cortical orientation selectivity remains controversial.

In this context, OS in the retina, first described by Levick (1967), provides an interesting counterpoint. Levick documented the presence of two distinct populations of OFF-center cells in rabbit: one that preferred extended bars aligned with the visual streak (horizontally oriented), and a second class that preferred vertically oriented stimuli. From extracellular spike recordings, Levick discounted a simple feedforward model comprising an asymmetry in the arrangement of excitatory inputs. He proposed that the inhibitory surround, normally present for concentric cells, was missing along the preferred orientation axis, such that the flanking inhibitory inputs only suppressed responses to nonpreferred orientations. Consistent with this notion, a subsequent pharmacological study showed that orientation selectivity could be blocked by application of picrotoxin, suggesting a role for GABAergic inhibition (Caldwell et al., 1978). More recently, Bloomfield (1994) described orientation-selective amacrine cells (ACs) and ganglion cells (GCs) in the rabbit retina, and showed, in line with previous work, that inhibition was essential to generate orientation selectivity. He also described orientation-biased amacrine cells with elongated dendritic arbors. Our understanding of the synaptic mechanisms generating orientation selectivity has advanced little since these earlier studies. In this paper, we determine the synaptic basis for orientation selectivity in rabbit retinal ganglion cells. Surprisingly, distinct synaptic mechanisms are used for horizontal and vertical orientations. 


\section{Materials and Methods}

Retina preparation, morphology, and patch recording. Experiments involving animals were performed in accord with National Institutes of Health guidelines, and the anesthesia and euthanasia protocols were approved by the Institutional Animal Care and Use Committee at Oregon Health and Science University. Pigmented rabbits of either sex were darkadapted for at least $1 \mathrm{~h}$ before isolating the retina. After dark-adaptation, all procedures were performed under dim-red or infrared illumination. A piece of inferior retina $\sim 10 \times 10 \mathrm{~mm}$ was placed in a recording chamber ( $\sim 0.5 \mathrm{ml}$ volume) and continuously perfused at $2-5 \mathrm{ml} / \mathrm{min}$ with Ames medium (Ames and Nesbett, 1981) (U.S. Biologicals) at $32-34^{\circ} \mathrm{C}$, $\mathrm{pH}$ 7.4. The piece was placed in the chamber so that a horizontal stimulus on a CRT computer monitor was orthogonal to the visual streak, and this orientation was kept consistent throughout the experiments. Patch electrodes were pulled from borosilicate glass to a final resistance of $4-6 \mathrm{M} \Omega$. For extracellular recording, the electrodes were filled with Ames medium. For whole-cell recordings, the electrodes contained the following: 125 mm Cs-methylsulfonate, 6 mm CsCl, 2 mm Mg-ATP, 1 mм Na-GTP, 1 mM EGTA, 10 mM Na-HEPES, $2.5 \mathrm{~mm}$ phosphocreatine disodium salt, and $3 \mathrm{~mm}$ QX-314-chloride. The solution was adjusted to $\mathrm{pH} 7.4$ using $\mathrm{CsOH}$ for voltage-clamp recording. The chloride reversal potential was calculated to be $-70 \mathrm{mV}$. Voltages were corrected for a calculated liquid junction potential of $-16 \mathrm{mV}$. Current and voltage signals were filtered at $2 \mathrm{kHz}$ (four-pole Bessel) and digitized with a sampling period of 100 $\mu$ s. Further filtering was performed during subsequent data analysis.

Pharmacological agents were added directly to the superfusion solution. The drugs used were as follows: SR 95531 (6-imino-3-(4methoxyphenyl)-1(6H)-pyridazinebutanoic acid hydrobromide, 10 $\mu \mathrm{M}$, Tocris Bioscience \# 1262), TPMPA [(1,2,5,6-tetrahydropyridin-4yl)methylphosphinic acid, $30 \mu \mathrm{M}$, Sigma \# T200], strychnine (1 $\mu \mathrm{M}$, Sigma \# S-8753), D-AP5 [D-(-)-2-amino-5-phosphonopentanoic acid, $50 \mu \mathrm{M}$, Asc-003].

Intracellular labeling. Orientation-selective ganglion cells (OS-GCs) were intracellularly injected with Alexa 594 (4 mM in intracellular solution, Alexa Fluor 594 hydrazide, Invitrogen \# A10438) (van Wyk et al., 2009). The retina was fixed for $15 \mathrm{~min}$ with $4 \%$ paraformaldehyde (PFA) in $0.1 \mathrm{M}$ phosphate buffer (PB; pH 7.4) and subsequently washed in $0.1 \mathrm{M}$ PBS, pH 7.4. Confocal micrographs were acquired on a Zeiss LSM 510 confocal microscope with $40 \times$ oil-immersion objective (NA $=1.3)$. Images illustrating the dendritic morphology show a vertical projection of several confocal sections through the retina. The contrast and brightness levels of the images were adjusted using ImageJ (rsb.info.nih.gov/ij/). In some cases, extraneous fluorescence was removed using Adobe Photoshop, to increase the clarity of the filled cells. This was sometimes required near the soma, where some dye spread was occasionally observed.

Light stimulation and recording. Light stimuli were generated on a CRT computer monitor at a refresh rate of $60 \mathrm{~Hz}$. The monitor screen was projected onto the retina through a $20 \times, 0.95 \mathrm{NA}$ water-immersion objective (Olympus) and brought into focus on the photoreceptor outer segments. The percentage stimulus contrast was defined as $C=$ $100\left(L_{\text {stimulus }}-L_{\text {background }}\right) / L_{\text {background }}$, and was set to $-60 \%$, unless otherwise indicated. The background light intensity measured $150 \mu \mathrm{W} / \mathrm{m}^{2}$ at the photoreceptor outer segments, which for the green phosphor of the stimulus monitor corresponds to 400 photons $/ \mu \mathrm{m}^{2} / \mathrm{s}$. Assuming a collecting area for rabbit rods of $\sim 1 \mu \mathrm{m}^{2}$, and half-maximal saturation for a light-adapted mammalian rod of $\sim 100$ photons $/ \mu \mathrm{m}^{2} / \mathrm{s}$ (Dunn et al., 2006), the background intensity was well above the scotopic range. The standard stimulus was a bar $1000 \mu \mathrm{m}$ long $\times 100$ $\mu \mathrm{m}$ wide, centered on the receptive field of the cell, either in the vertical or horizontal orientation.

Data analysis. Light-activated synaptic conductances were measured as described previously, with some additional modifications (van Wyk et al., 2009). Membrane currents were recorded at nine holding potentials from -116 to $+4 \mathrm{mV}$ in $15 \mathrm{mV}$ increments. At each potential, the $1 \mathrm{~s}$ light stimulus was delivered. Series resistance was measured from the average of a series of $-10 \mathrm{mV}$ voltage steps, just before each of these stimulus sets. In a sample of 25 cells, series resistance averaged $15.6 \pm 3.8$ $\mathrm{M} \Omega$. Synaptic conductance was measured from current-voltage $(I-V)$ relations. $I-V$ relations were constructed every $10 \mathrm{~ms}$, starting at $t=0.4 \mathrm{~s}$, $200 \mathrm{~ms}$ before stimulus onset, and ending at $t=2.5 \mathrm{~s}, 2.1 \mathrm{~s}$ later. The membrane potentials for each $I-V$ were corrected for the measured series resistance, i.e., $V_{\text {corr }}=V_{\mathrm{m}}-I_{\mathrm{m}} R_{\mathrm{s}}$. These voltage-corrected $I-V$ relations were interpolated using cubic spline interpolation, and resampled at nine fixed voltages ranging from -100 to $-4 \mathrm{mV}$ in $12 \mathrm{mV}$ increments. The net light-activated, series-resistance corrected $I-V$ relations were then calculated as the difference between each interpolated $I-V$ relation and the interpolated $I-V$ at $t=0.4$, which represented the prestimulus, background $I-V$ relation. To obviate errors in the measurement of the net light-activated currents that would be introduced by the sloping baselines particularly evident at positive potentials (e.g., see Figs. $2 B, C$, $6 B, C$ ), a linear trend between $t=0.4 \mathrm{~s}$ and $t=2.1 \mathrm{~s}$ was subtracted before calculating the differences. This trend was added back to produce the predicted currents shown in the figures.

The light-evoked inhibitory and excitatory synaptic conductances were calculated from these interpolated $I-V$ relations. As shown in the results, excitation included contribution from NMDA receptors, which have a nonlinear current-voltage relation, caused by magnesium block of open channels. Accordingly, conductances were resolved into linear and nonlinear components by fitting the $I-V$ relations with the following equation:

$$
I_{\mathrm{m}}=I_{0}+\left(G_{1}+G_{2} f(V)\right) V,
$$

where $0 \leq f(V) \leq 1$ accounted for the voltage dependence of $G_{2}$. We assumed that any nonlinearity in the net light-activated $I-V$ relations resulted from NMDA currents, and therefore, we will refer to the nonlinear component, $G_{2}$, as $G_{\mathrm{NMDA}}$. The fraction of open NMDA channels as a function of voltage was calculated as follows (Woodhull, 1973):

$$
f(V)=1-\left[\mathrm{Mg}_{\mathrm{o}}\right] /\left(\left[\mathrm{Mg}_{\mathrm{o}}\right]+K_{\mathrm{d}} \exp \left(V / V_{\delta}\right)\right),
$$

where $\left[\mathrm{Mgo}_{\mathrm{o}}\right]$ is the external magnesium concentration, here $1.2 \mathrm{~mm}, K_{\mathrm{d}}$ is the magnesium dissociation constant at $0 \mathrm{mV}$, and $V_{\delta}$ governs the equivalent distance through the membrane electric field for the magnesium binding site (Ascher and Nowak, 1988). For the analysis of all the data presented, these parameters were fixed at $K_{\mathrm{d}}=180 \mathrm{~mm}$ and $V_{\delta}=15 \mathrm{mV}$. These values were arrived at empirically, by fitting Equation 1 to $I-V$ relations during GABAergic block (see Fig. $8 C 2$ ), with $K_{\mathrm{d}}$ and $V_{\delta}$ as free parameters. These parameters produced very good fits to the data, as evident from the example $I-V$ relations shown in Figures 2-10, and accounted for the nonlinearity in the $I-V$ relations for both the vertically selective ganglion cells (VS-GCs) and horizontally selective ganglion cells (HS-GCs). The $K_{\mathrm{d}}$ is higher than generally reported, indicating unusually low Mg affinity. Triheteromeric channels comprising NR1/NR2A/NR3A subunits have been reported to have low $\mathrm{Mg}$ binding affinity (Sasaki et al., 2002; Tong et al., 2008).

The synaptic reversal potential for each $I-V$ relation, $V_{\mathrm{L}}$, was the potential where the $I-V$ crossed the voltage axis, i.e., $-I_{0} /\left(G_{1}+G_{\mathrm{NMDA}}\right)$. The linear component of the conductance, $G_{1}$, is assumed to comprise two components, an excitatory component, $G_{\mathrm{E}}$, with a reversal potential of $V_{\mathrm{E}}=0 \mathrm{mV}$ and an inhibitory component, $G_{\mathrm{I}}$, with a reversal potential of $V_{\mathrm{I}}=-70 \mathrm{mV}$, the chloride equilibrium potential for the solutions used. The nonlinear NMDA conductance, $G_{\mathrm{NMDA}}$, had a reversal potential at $V_{\mathrm{E}}$. If $G_{\text {Total }}=G_{1}+G_{\mathrm{NMDA}}$, then the excitatory conductance is given by $G_{\mathrm{E}}=G_{\text {Total }}\left(V_{\mathrm{L}}-V_{\mathrm{I}}\right) /\left(V_{\mathrm{E}}-V_{\mathrm{I}}\right)$, and the inhibitory conductance is given by $G_{\mathrm{I}}=G_{\text {Total }}\left(V_{\mathrm{L}}-V_{\mathrm{E}}\right) /\left(V_{\mathrm{I}}-V_{\mathrm{E}}\right)$. The linear component of the excitation was presumably AMPA/kainate mediated and was obtained as $G_{\mathrm{A} / \mathrm{K}}=G_{\mathrm{E}}-G_{\mathrm{NMDA}}$. As noted, NMDA channels are blocked by magnesium at negative potentials and therefore contribute relatively less excitatory current than an equivalent linear conductance. Since the current generated by a conductance at a given membrane potential is pertinent for physiological responses, we have scaled the fitted NMDA conductance in all figures to represent the chord conductance at a nominal resting potential of $-70 \mathrm{mV}$ (Manookin et al., 2010). Using the parameters above to define the NMDA conductance, the chord conductance at $-70 \mathrm{mV}$ is $58 \%$ of the equivalent linear conductance.

These procedures were applied to the data from individual cells. Alternatively, the raw current responses from a group of cells were averaged 
VERTICALLY-SELECTIVE

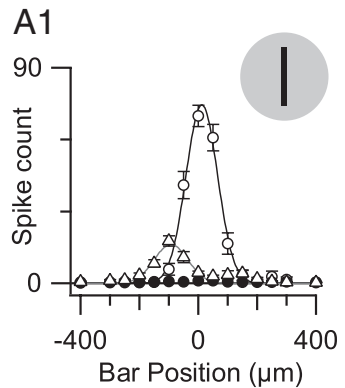

B1
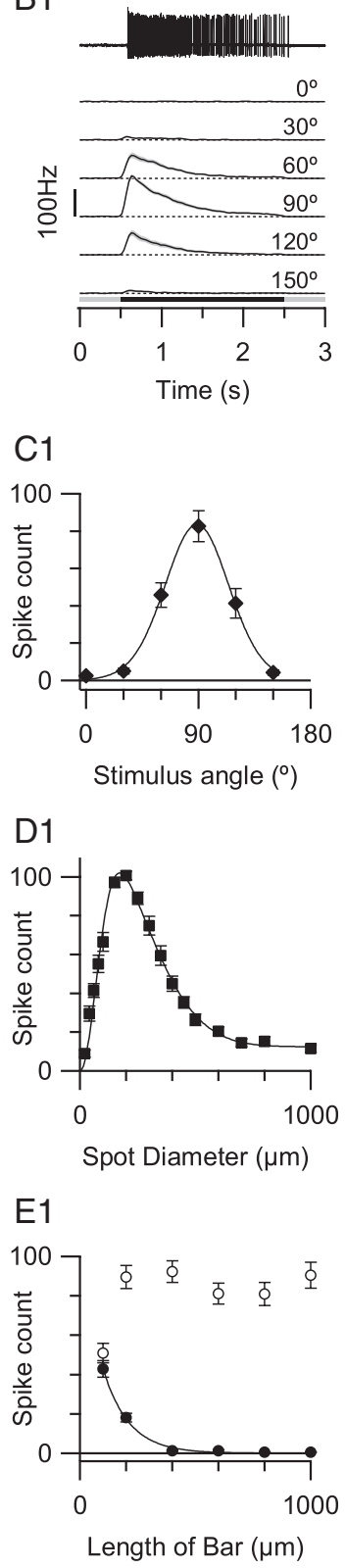

HORIZONTALLY-SELECTIVE
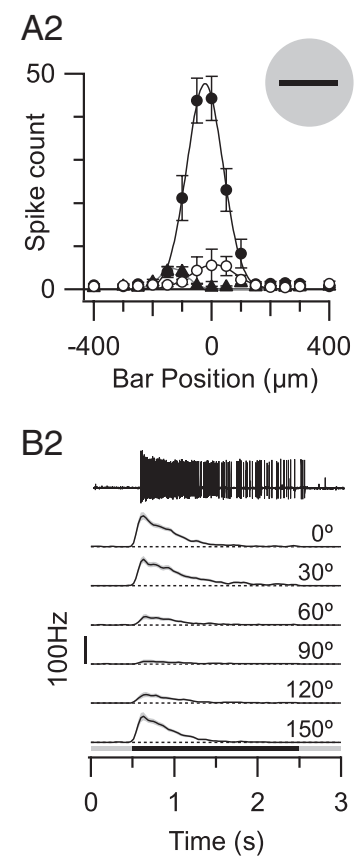

$\mathrm{C} 2$
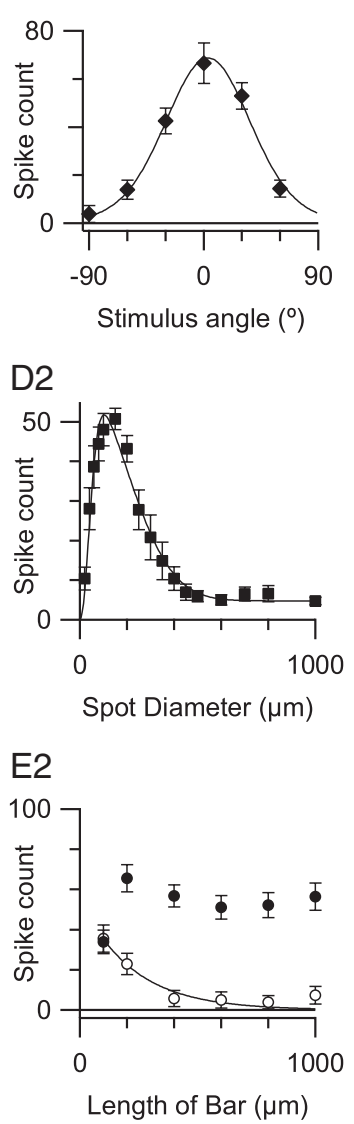

Figure 1. Identification of orientation-selective $\mathrm{GCs}$ from spiking properties. In this and all subsequent figures, open circles and solid circles denote data obtained from vertically and horizontally oriented bars, respectively. Unless otherwise noted, the stimulus bar comprised a dark bar ( $60 \%$ negative contrast), $1 \mathrm{~mm}$ long $\times 100 \mu \mathrm{m}$ wide, centered on the receptive field of the cell. For $\boldsymbol{A}-\boldsymbol{C}$ and $\boldsymbol{E}$, responses were averaged from 21 VS-GCs and $15 \mathrm{HS}-\mathrm{GCS}$. $\boldsymbol{A}$, Average responses elicited by a vertically or horizontally oriented stimulus bar flashed at a range of positions along the orthogonal axis. Orientation-selective ganglion cells responded in one of two orientations for the bar stimulus, vertical $(\boldsymbol{A} 1)$ or horizontal $(\boldsymbol{A 2})$. The maximal response was observed when the bar was centered on the receptive field. $\boldsymbol{B}$, Extracellular recordings of together, and the analysis procedures were applied to these averaged current responses. In this case, the series resistance was corrected using the average value for the group of cells. The two approaches, the cell-bycell analysis and the group analysis, produced essentially the same results, and the group analysis was used for the data illustrated in the figures. Cell-to-cell variability in the responses is shown by the SE bars in the example $I-V$ relations shown in the figures. These were calculated across the $I-V$ relations obtained when the analysis was applied to each individual cell.

For the HS-GCs, the outward current at the most positive potentials during orthogonal stimulation appeared to be sublinear. Rather than attempting to account for this behavior by adding another nonlinear component, we ignored the two most positive data points during fitting. It is possible that this nonlinearity resulted from incomplete space clamp at positive potentials, but in any case, this approximation does not affect the central conclusions of the study.

The von Mises distribution, which is the circular analog to the Gaussian distribution, was used to describe the tuning curves of the OS-GCs shown in Figure $1 C$, and is given by the following:

$$
R=R_{\max } e^{(\kappa \cos ((x-\mu) \pi / 180))} / e^{\kappa}
$$

where $R_{\max }$ is the maximum response, $\mu$ is the preferred orientation in degrees, and $\kappa$ accounts for the width of the orientation tuning.

\section{Results}

\section{Physiological and morphological identification}

OS-GCs located close to the visual streak were targeted by making extracellular loose patch recordings of action potentials at the soma. Of the orientation-selective cells we recorded, most were OFF-center cells; ON-center OS cells were rarely encountered. Therefore, we have focused exclusively on the OFF-center OS cells. As has been observed previously, orientation tuning obtained from the average peak spike discharge divided the cells into two groups, one that responded most strongly to vertical bars (21 cells) and the other to horizontal bars ( 15 cells) (Fig. $1 \mathrm{~A}$ ). We will refer to the two classes as VS-GCs and HS-GCs. In all figures, open circles refer to vertically orientated stimuli and solid circles refer to horizontally orientated stimuli. Unless otherwise noted, the stimulus bar dimensions were $1000 \mu \mathrm{m}$ by $100 \mu \mathrm{m}$. Extracellular recordings of single stimuli at the preferred orientations from a representative VS-GC and an HS-GC are shown in Figure $1 \mathrm{~B}$. Analysis of the average peristimulus time histograms (PSTHs) indicate that the spike-rate of the OS-GCs during $2 \mathrm{~s}$ flashes reached a peak in $\sim 130 \mathrm{~ms}$ and declined thereafter with a time constant of $\sim 0.5 \mathrm{~s}$ (Fig. $1 B$ ). The time course and amplitude

$\leftarrow$

single stimuli at the preferred orientations from representative cells are shown at the top of each panel. Average PSTHs illustrate the spiking behavior when the orientation of a centered bar was changed. For both cell types, the spike discharge peaked in $\sim 130 \mathrm{~ms}$ and declined exponentially with time constants of 530 and 405 ms for VS-GCS and HS-GCS, respectively (B1, $B 2$ ). Shaded regions show the SEs of the responses. $C$, Orientation tuning was well described by a von Mises distribution (solid fitted lines, C1, (2). The preferred orientations obtained from the peaks of the fitted lines were $89.1^{\circ}$ and $3.6^{\circ}$. The widths at half-height obtained from the fitted lines were $61^{\circ}$ and $76^{\circ}$ for the VS-GCS and HS-GCS, respectively. D, Average responses to spot stimuli of increasing diameter (60\% negative contrast), in a subset of $17 \mathrm{VS}-\mathrm{GCS}$ and $13 \mathrm{HS}-\mathrm{GCS}$, displayed an apparent center-surround organization. The fitted curves show a DOG, with center diameters $(\sigma)$ of 105 and $55 \mu \mathrm{m}$ and surround diameters of $350 \pm 20$ and $275 \pm 20 \mu \mathrm{m}$ for the VS-GCS and HS-GCS, respectively. The surround suppressed the response to $9.4 \%$ and $7.7 \%$ of the peak in each case. The DOG fitted well for the VS-GCS (D1), but not so well for the HS-GCS (D2), particularly close to the peak. $\boldsymbol{E}$, For preferred orientation stimuli (E1, open symbols, E2, closed symbols), increasing the stimulus bar length produced little evidence of additional inhibition. The asymmetry of the surround is evident from the strong suppression of the responses as the bar length increased along the orthogonal axis (E1, closed symbols, E2, open symbols). The space constants for suppression were estimated from the exponentials fitted to the data (solid lines) and were 110 and $220 \mu \mathrm{m}$ for the VS-GCs and HS-GCs, respectively. 
of the PSTHs were essentially identical for the two cell classes. The OS-GCs did not generate spikes under constant background illumination. Occasionally spikes occurred at the termination of the preferred orientation stimulus (ON response) for VS-GCs and HS-GCs (Fig. $1 A$, triangles).

The orientation tuning for both groups was well approximated by the von Mises distribution, and the preferred orientations, obtained from the peaks of the fitted curves, were orthogonal to within $\sim 5^{\circ}$ (Fig. $1 C$ ). The VS-GCs were slightly more narrowly tuned than the HS-GCs, suggesting that there may be differences in the spatial structure of the receptive fields. The width of the excitatory centers, mapped with a bar, produced similar estimates of $150 \mu \mathrm{m}$ and $190 \mu \mathrm{m}$ for the VS-GCs and HS-GCs, respectively ( $2 \sigma$ of the fitted Gaussian) (Fig. $1 A)$. A further assessment of the center extents was obtained using circular stimuli of increasing diameter. The largest responses were observed for similar stimulus spot diameters of $\sim 170$ and $\sim 150$ $\mu \mathrm{m}$ for the VS-GCs and HS-GCs, respectively (Fig. 1D).

Previous work has suggested that orientation selectivity is produced by surround inhibition (Levick, 1967; Caldwell et al., 1978; Bloomfield, 1994), and an initial estimate of the extent of the surrounding inhibition was obtained using dark spots of increasing radius (Fig. $1 D$ ). The data for the VS-GCs were well described by a difference-of-Gaussian function (DOG) (Fig. 1D1), while the HS-GCs were relatively poorly fit by the DOG at small diameters (Fig. 1D2), suggesting differences in the center receptive field structure of the two cell types. Nonetheless, the data indicate that the spatial extent of the surrounding inhibition in the two cell classes was similar with widths of $350 \pm 20 \mu \mathrm{m}$ and $270 \pm 20$ $\mu \mathrm{m}$ for VS-GCs and HS-GCs, respectively. Although a symmetric DOG model provided a reasonable description of the arearesponse data, the surround is spatially oriented as demonstrated by the responses to vertically and horizontally oriented bars of different lengths (Fig. $1 E$ ). As the length of the bar was increased along the nonpreferred orientation, spiking was suppressed, and the exponential space constants for this effect, obtained from the solid lines, were 110 and $220 \mu \mathrm{m}$ for the VS-GCs and HS-GCs, respectively. The shorter inhibitory space constant for the VSGCs may partially explain the slightly sharper orientation tuning in these cells (Fig. 1C1). It is also noteworthy that responses to bars of increasing length became maximal at $\sim 200 \mu \mathrm{m}$ for both cell types, consistent with the similar center extents shown above (Fig. $1 E)$.

The morphological structure of the OS-GCs was visualized, and correlated with the physiological properties, by filling some recorded cells with the fluorescent dye Alexa-594 hydrazide (see Figs. 2A, 6A; supplemental Fig. S1, available at www.jneurosci. org as supplemental material). The identified cells illustrated reveal three main features. First, the soma placement was often asymmetric with respect to the dendritic arbors, but this was not related to the preferred orientation (Amthor et al., 1989). Second, the dendritic extent was similar to the physiological receptive field center size. Finally, the HS-GCs tended to be more densely branched and more diffusely stratified than the VS-GCs. The asymmetrical dendritic spread of the VS-GC shown in Figure $2 \mathrm{~A}$ resembles the OFF-direction-selective ganglion cells (DSGCs) reported by Kim et al. (2008), which were selective to upward motion in the mouse retina. We determined that the VS-GCs described here are not direction selective, by recording responses to moving bar stimuli as described previously (Taylor and Vaney, 2002). The directional selectivity index (DSI) was $0.039 \pm 0.011$ ( $n=6$; data not shown), which is much smaller than the DSI reported for the OFF-DSGCs in the mouse $[\sim 0.4$ (Kim et al.,
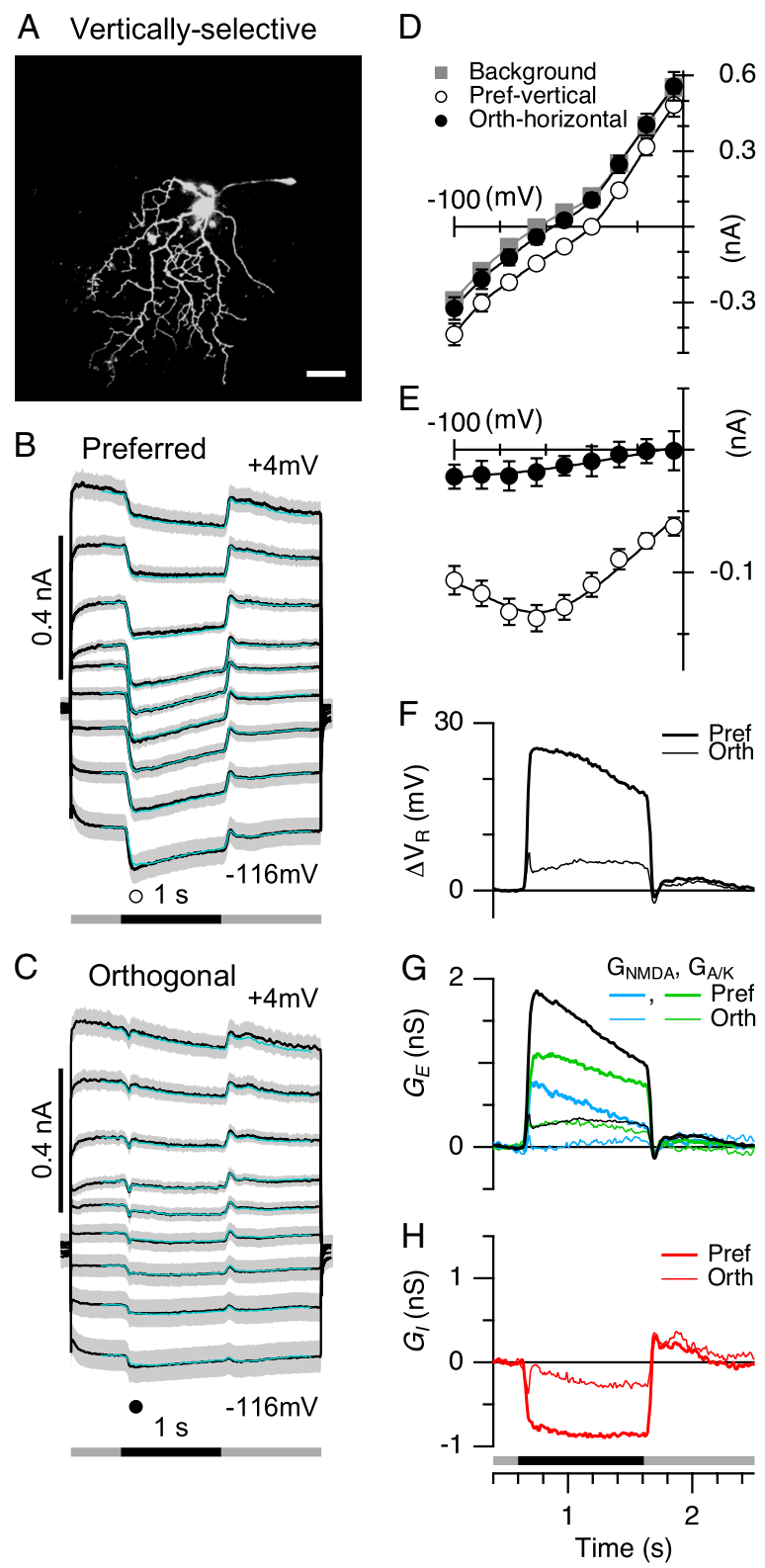

Figure 2. Ganglion cells selective for vertically oriented stimuli. VS-GCS were stimulated with dark bars of $60 \%$ negative contrast, $1 \mathrm{~mm}$ long and $100 \mu \mathrm{m}$ wide, flashed for $1 \mathrm{~s}$ in either the preferred or the orthogonal orientation. $A$, Dendritic morphology of a VS-GC reconstructed from serial confocal micrographs. Scale bar: $50 \mu \mathrm{m}$. B, C, Average currents from $26 \mathrm{VS}-\mathrm{GCS}$. The shaded regions show the SEs across the group of cells. The stimulus timing is shown beneath the traces. The cyan lines show the currents reconstructed from the fitted conductances shown in $\mathbf{G}$ and $\boldsymbol{H}$. Note that the fitted NMDA conductance in all figures is scaled to $58 \%$ to represent the chord conductance at $-70 \mathrm{mV}$. The symbols below the traces show the time points for the $\mathrm{I}-\mathrm{V}$ plots shown in $\boldsymbol{D}$ and $\boldsymbol{E}$. $\boldsymbol{D}$, Whole-cell current-voltage relations averaged from the 26 cells used in $\boldsymbol{A}$ and $\boldsymbol{B}$ at rest (gray symbols), and during preferred (open black circles) and orthogonal (closed black circles) stimulation. Error bars show the SEs for the group of cells, where they are larger than the symbols. $\boldsymbol{E}$, Net light-evoked component of the current obtained by subtracting the gray symbols from the open and closed symbols in $\boldsymbol{D}$. The solid lines through the points show example fits to the $I-V$ relations that were used to derived the synaptic conductance (see Materials and Methods). The error bars show the SEs for the average $I-V$ relation at this time point for the group of cells. $\boldsymbol{F}$, Change in the whole-cell zero-current potential, $V_{R}$, as a function of time during the light stimulation. The thick line shows the preferred orientation, and the thin line shows the orthogonal. G, Total excitatory conductance activated during preferred (thick black lines) and orthogonal (thin black lines) stimulation. The total excitation is the sum of the nonlinear NMDA component (blue) and the linear AMPA/kainate component (green). $\boldsymbol{H}$, Inhibitory conductance is suppressed during preferred (thick red) stimulation, but not strongly modulated during orthogonal (thin red) stimulation. 
2008)]. The asymmetric dendritic arbor along with the tracer coupling to amacrine cells (supplemental Fig. $1 B$, available at www.jneurosci.org as supplemental material) suggests that these cells could be the OFF-coupled cells reported by Roska et al. (2006).

\section{Synaptic mechanisms}

The results thus far serve to identify the OS cells in the rabbit based on physiological responses, and confirm the presence of two major classes with spiking properties that differ mainly with regard to the preferred orientation. Although the spiking phenotypes are very similar, differences in dendritic structure and in the inhibitory space constants raise the possibility that the two OS classes receive input from diverse amacrine and bipolar cells. We next asked whether the synaptic mechanisms that generate the OS responses were similar between the two OS classes. To address this, we voltage clamped the cells and recorded the synaptic activity while stimulating with bars in the preferred and orthogonal orientations. We found qualitative and quantitative differences in the synaptic inputs to the two groups of cells that reveal underlying differences in the synaptic mechanisms. These differences are illustrated in the following figures and summarized by a proposed circuit model.

\section{Vertically selective cells}

An example of a VS-GC morphology is shown in Figure $2 \mathrm{~A}$. In a group of 26 such cells, the averaged currents evoked by preferred stimuli over a range of membrane potentials were inward and of similar net amplitude (Fig. 2 B). Thus, stimulation did not change the slope of the whole-cell current-voltage relation, but produced a net inward current at all potentials (Fig. 2D, compare gray squares and open circles). In contrast, orthogonal stimulation evoked little response (Fig. 2C,D, solid circles). Thus, spiking elicited by preferred orientation stimuli appears to be produced by a depolarizing shift in the whole-cell zero-current potential of close to $+25 \mathrm{mV}$ (Fig. $2 \mathrm{~F}$, thick solid trace). The net light-evoked currents driving this shift revealed marked nonlinearity (Fig. $2 E$, open circles), characterized by relatively larger inward currents at intermediate potentials, which could be accounted for by including an NMDA component (Fig. 2G, thick blue trace) (see Materials and Methods). The net light-evoked inward current at positive potentials was accounted for by the presence of a standing inhibitory conductance of $\sim 1 \mathrm{nS}$, which was suppressed by preferred stimulation (Fig. $2 \mathrm{H}$, thick red trace). Further evidence for this finding is that membrane current variance was suppressed during the light stimulation, consistent with the loss of a variable synaptic input.

The cyan lines overlying the averaged data in Figure 2, $B$ and $C$, and subsequent figures were generated from the calculated conductances (e.g., Fig. $2 G, H$ ), and demonstrate that the estimated conductances, which incorporate correction for the series resistance, accurately reproduced the original data. In summary, synaptic excitation during preferred stimulation comprised a relatively transient NMDA-mediated component, which peaked at $\sim 0.75 \mathrm{nS}$ (Fig. $2 G$, thick blue line) (chord conductance at -70 $\mathrm{mV}$ ), a sustained non-NMDA AMPA/kainate component of $\sim 1$ $\mathrm{nS}$ (Fig. 2G, thick green line), and sustained disinhibition of $\sim 1$ $\mathrm{nS}$ (Fig. $2 H$, thick red line). During orthogonal stimulation, the center-response was strongly suppressed (Fig. 2D, solid circles), and the residual net light-evoked $I-V$ was linear (Fig. $2 E$, solid circles). The results indicate that orthogonal stimulation produced strong suppression of the linear excitatory component (Fig. 2G, thin green line), complete suppression of the NMDA component (Fig. 2G, thin blue line), and much less modulation of the sustained inhibitory component (Fig. $2 \mathrm{H}$, thin red line). The black traces in Figure $2 G$ represent the total excitatory conductance (i.e., $G_{\mathrm{NMDA}}+G_{\mathrm{A} / \mathrm{K}}$ ) for the preferred (thick line) and orthogonal (thin line) orientations, and illustrate that orthogonal excitation is entirely accounted for by the linear excitatory conductance.

If the nonlinear component is due to NMDA receptors, then it should disappear during application of $50 \mu \mathrm{M} \mathrm{D}-\mathrm{AP} 5$, a specific NMDA receptor antagonist. In a smaller sample of cells $(n=5)$, the general properties of the conductances under control conditions (Fig. 3A1-E1) were very similar to that shown in Figure 2, including a significant, relatively transient NMDA component (Fig. 3D1, thick blue line). Application of the NMDA antagonist strongly suppressed the nonlinearity of the preferred $I-V$ relation (Fig. 3C2), consistent with suppression of the NMDA component (Fig. 3A2-E2). The total excitatory conductance (Fig. 3D2, black lines) in the presence of D-AP5 was accounted for by the AMPA/ kainate conductance (Fig. 3D2, green lines). It is noteworthy that the D-AP5 barely affected the time course and amplitude of the linear excitatory component (Fig. 3D, compare green traces) and the inhibition (Fig. $3 E$ ), suggesting that the synaptic circuitry generating the orientation selectivity of these inputs is not mediated via NMDA receptors.

Previous work (Caldwell et al., 1978) has shown that orientation selectivity is abolished by picrotoxin at concentrations that block GABAergic transmission. The resolution of separate excitatory and inhibitory inputs to the VS-GCs allowed us to determine the synaptic mechanisms producing this effect. For three cells, we applied $10 \mu \mathrm{M}$ SR95531 to block GABA $_{\mathrm{A}}$ receptors, and in another three cells, we applied both the $\mathrm{GABA}_{\mathrm{A}}$ antagonist and a GABA $_{C}$ antagonist (30 $\mu \mathrm{M}$ TPMPA). The majority of the inhibition appears to be mediated by $\mathrm{GABA}_{\mathrm{A}}$ receptors, because there was no discernible additional effect on the synaptic responses upon addition of TPMPA. Data for all six cells are combined in Figure 4. GABA receptor blockade produced an increase in the net light-evoked currents during preferred stimulation (Fig. $4 A 2$ ), and revealed similar amplitude currents during orthogonal stimulation (Fig. 4 B2). The activation phase of the NMDA component was somewhat blunted by GABAergic block, and the conductance lost its orientation preference. Similarly, orthogonal suppression of the linear and nonlinear excitation was less (Fig. $4 \mathrm{D} 2$, thin green and blue lines), which is evident in the increase in total conductance (Fig. 4D1,D2, thin black lines). The preferred AMPA/kainate conductance was potentiated during GABAergic block (Fig. 4D1,D2, thick green lines) and retained some orientation selectivity, while the amplitude of the preferred NMDA component (Fig. 4D2, thick blue line) was relatively unaffected, but became completely insensitive to orientation. The disinhibition, which was moderately potentiated by GABAergic block, also became independent of orientation (Fig. 4E2, red traces). In summary, GABAergic block abolishes orientation selectivity of spiking in two ways: by preventing the suppression of excitation and by preventing the suppression of disinhibition. However, the data indicate that there is a small residual OS signal that is resistant to GABAergic block and is evident as a difference in the magnitude of the total excitation (Fig. 4D2, thick and thin black lines).

Since the disinhibition is resistant to GABA blockers (Fig. 4E), it is most likely mediated by glycine receptors. This expectation was confirmed by applying $1 \mu \mathrm{M}$ strychnine, a glycine receptor antagonist. As in the previous figures, the control from a smaller sample of cells $(n=10)$ is shown in Figure 5A1-E1. Strychnine 

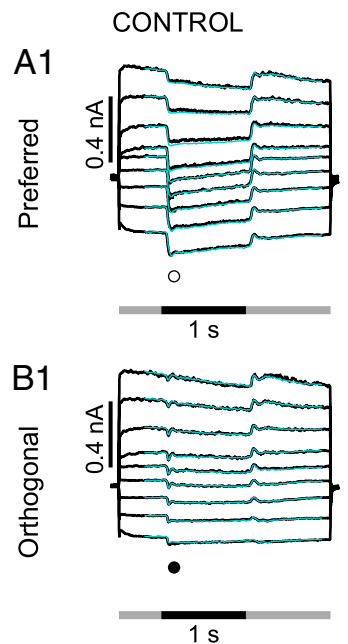

C1
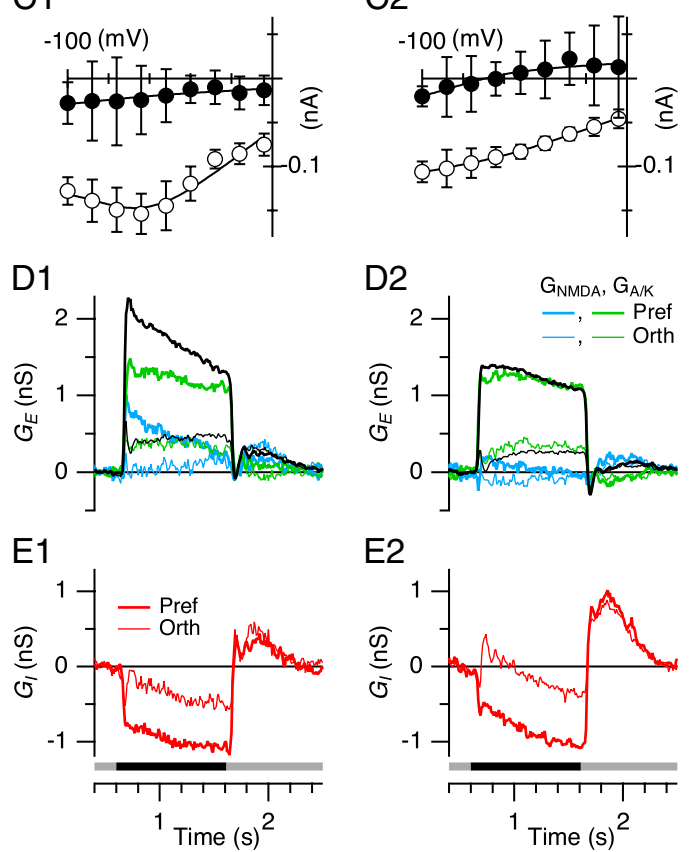

E2

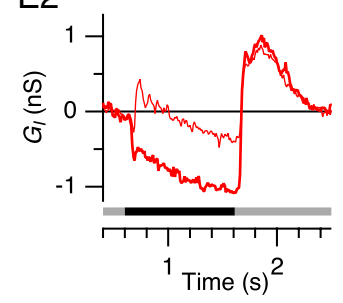

Figure 3. NMDA receptor antagonist blocks the nonlinear component in VS-GCs. The first column shows the control data (A1-E1), and the second column shows the effects of a $50 \mu \mathrm{m}$ concentration of the NMDA antagonist D-AP5 (A2-E2). Marker and line conventions are identical to Figure 2. $A, B$, Membrane currents averaged from five cells, overlaid with the predicted currents from the conductance analysis. $C$, Net light-evoked current-voltage relations obtained by subtraction as for Figure $2 E$, and measured during preferred and orthogonal stimulation. The NMDA antagonist completely suppressed the nonlinear component of the $I-V$ relations (C2).D, $\boldsymbol{E}$, Net light-evoked synaptic conductances obtained by analyzing the data in $\boldsymbol{A}$ and $\boldsymbol{B}$. Note that the linear component of the excitation ( $g r e e n, \boldsymbol{D}$ ) and the inhibitory component $(\boldsymbol{E})$ were unaffected by the NMDA antagonist. In the presence of D-AP5, the AMPA/kainate component (green) alone accounts for the total excitatory conductance (black).

suppressed the sustained disinhibition in the preferred orientation by $>90 \%$ during the light stimulus (Fig. 5E2, thick red trace), consistent with a direct glycinergic input. A residual inhibitory component revealed in the presence of strychnine appears to be larger in the orthogonal orientation (Fig. 5E2, thin red line) than the preferred, which is consistent with the orientation selectivity of the cells. The application of strychnine also partially suppressed excitatory inputs ( $\sim 50 \%)$ (Fig. 5D2, black lines); however, the synaptic inputs remained orientation selective (Fig. $5 C 2, D 2, E 2)$. Thus, glycine receptors mediate direct inhibition,
CONTROL

A1

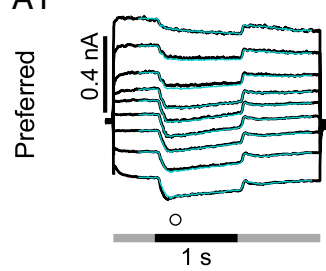

B1

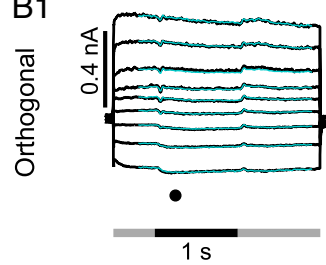

C1
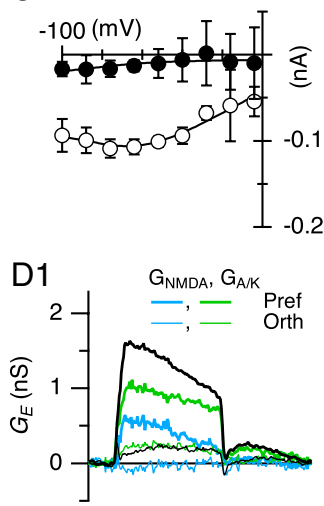

E1

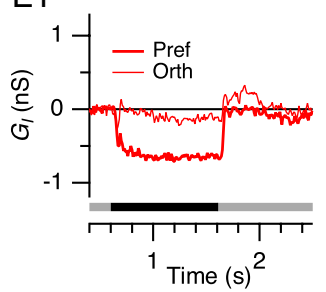

\section{GABA BLOCK}

A2

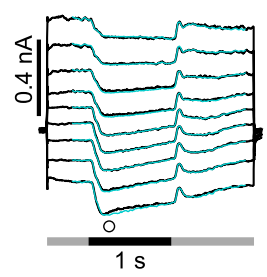

B2

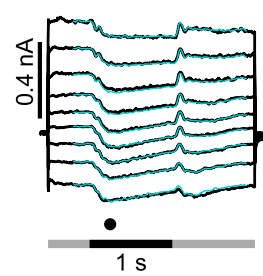

C2

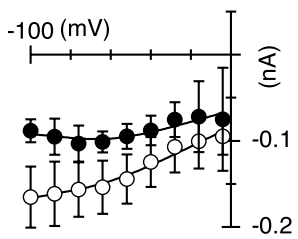

D2

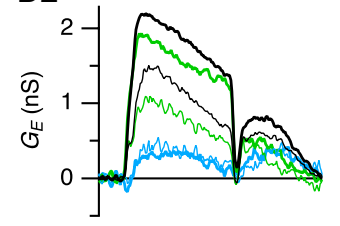

E2

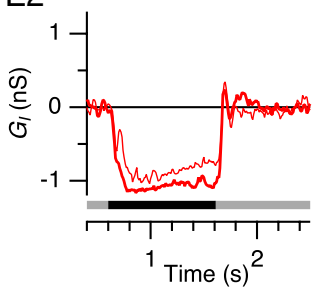

Figure 4. $G A B A_{A}$ and $G A B A_{C}$ receptor antagonists suppress orientation selectivity in VS-GCS. The first column shows the control data (A1-E1), and the second column shows the effects of coapplication of $10 \mu \mathrm{m}$ SR-95331 and $30 \mu \mathrm{m}$ TPMPA (A2-E2). Marker and line conventions are identical to Figure 2. $A, B$, Membrane currents averaged from six cells, overlaid with the predicted currents from the conductance analysis. Blocking GABA receptors increased the net lightevoked currents during orthogonal stimulation (compare $\boldsymbol{B} \mathbf{1}$ and $\boldsymbol{B 2}$ ). $\boldsymbol{C}$, Net light-evoked current-voltage relations obtained by subtraction as for Figure $2 E$, and measured during preferred (open circles) and orthogonal (closed circles) stimulation. Blocking GABA receptors prevented suppression of excitation during orthogonal stimulation (compare D1 and D2), and removed the orientation selectivity of the inhibition $(\boldsymbol{E})$. Total excitation and inhibition were enhanced by GABAergic block.

but are not critical for generating the orientation selectivity of the excitatory synaptic inputs. The effects of strychnine are unlikely to be mediated by suppression of the rod pathway at the glycinergic AII amacrine cell to OFF cone-bipolar cell synapse (Müller et al., 1988), since the background intensity normally used was expected to saturate rod signaling, but to be certain, the background light intensity was raised $1 \log$ unit for the experiments illustrated in Figure 5 (and also in Fig. 9 below). Moreover, a generalized suppression of rod signaling through the OFF pathway might be expected to suppress excitation and inhibition similarly, in the case that the postsynaptic inhibition was GABAergic. 


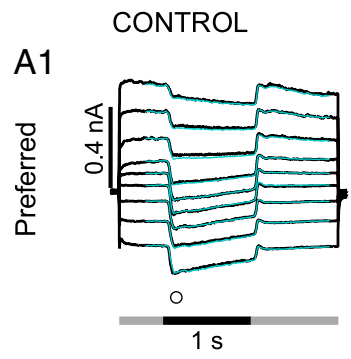

\section{A2}

GLYCINE BLOCK

B1

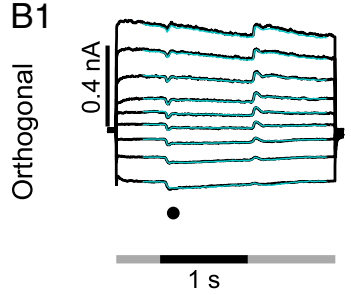

C1
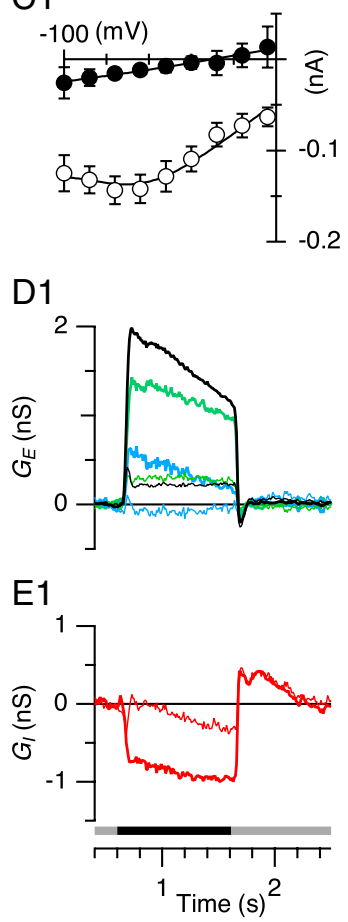

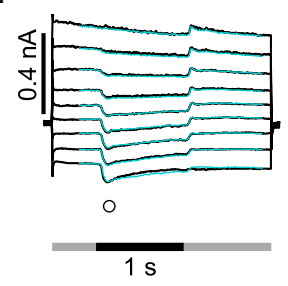

B2

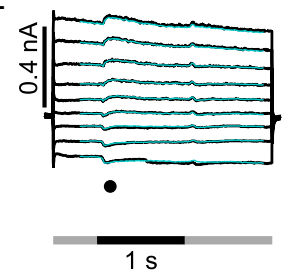

C2

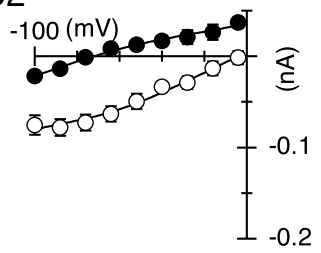

D2

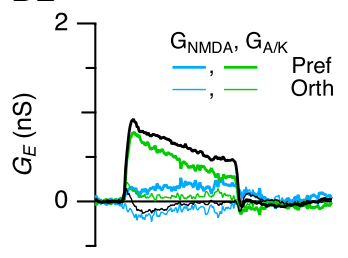

E2

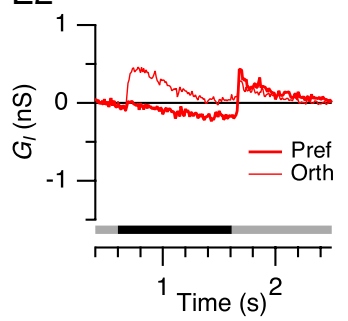

Figure 5. Glycine receptor antagonist suppresses disinhibition in VS-GCS. The background intensity normally used was above the scotopic range, and therefore any effects of strychnine are unlikely to be due to suppression of the glycinergic synapse between All-amacrine cells and OFF-cone bipolar cells. Nonetheless, to rule out this possibility, some of these recordings were performed using background light intensities 1 log unit higher than usual, but the contrast was maintained at $60 \%$. The first column shows the control data (A1-E1), and the second column shows the effects of $1 \mu \mathrm{M}$ strychnine (A2-E2). Marker and line conventions are identical to Figure 2. $A, B$, Membrane currents averaged from 10 cells, overlaid with the predicted currents from the conductance analysis. $\boldsymbol{C}$, Net light-evoked current-voltage relations obtained by subtraction as for Figure $2 E$, and measured during preferred (open circles) and orthogonal (closed circles) stimulation. D, Blocking glycine receptors partially suppressed excitatory inputs (compare $\mathbf{D} 1$ and $\mathbf{D 2}$ ) but strongly suppressed the sustained disinhibition during preferred stimulation (compare $\boldsymbol{E} 1$ and $\boldsymbol{E} 2$ ), and revealed a transient increase in inhibitory conductance during orthogonal stimulation.

Thus, the stronger blocking effect of strychnine on the inhibition is most simply accounted for by the presence of postsynaptic glycine receptors on the VS-GCs. Finally, under identical stimulus and recording conditions, strychnine failed to affect components of the synaptic inputs to the HS-GCs (see below), which indicates that strychnine does not act by a generalized suppression of signaling through the rod pathway in these preparations.

\section{Horizontally selective cells}

An example of a HS-GC morphology is shown in Figure 6A. The stimuli and recording conditions for analyzing HS-GCs were identical to those for the VS-GCs. Examination of the average current responses from 17 such cells (Fig. $6 B, C$ ) revealed similarities along with marked differences compared with the VSGCs. The most obvious difference between the two groups is that the HS-GCs receive an increase in synaptic drive during orthogonal stimulation (Fig. 6C), in stark contrast to the VS-GCs, in which synaptic input is suppressed (Fig. 2C). The result is that the whole-cell input conductance is higher during orthogonal stimulation (Fig. 6D, open circles), and the zero-current potential hyperpolarizes from the resting value (Fig. $6 F$ ). The net lightevoked current near the peak of the response is dominated by direct inhibitory inputs [Fig. $6 E$ (open circles), $H$ (thin red line)].

During preferred stimulation, the inhibitory component is markedly reduced and comprises transient inputs at stimulus onset and termination (Fig. $6 \mathrm{H}$, thick red trace), while the excitation, similar to the VS-GCs, includes a sustained linear AMPA/ kainate component (Fig. 6G, thick green line) and a relatively transient NMDA component (Fig. 6G, thick blue line), the net sum of which is shown by the thick black trace (Fig. $6 G$ ). Unlike the VS-GCs, both the preferred AMPA/kainate and NMDA components of excitation (Fig. 6G, thick green and blue lines) are of similar magnitude. In contrast to the VS-GCs, where excitation is mediated in part by glycinergic disinhibition, spiking responses in HS-GCs are driven entirely by increases in excitatory drive to the cells.

Similar to the VS-GCs, we wanted to obtain direct evidence that the nonlinearity of the $I-V$ relations observed in the HS-GCs was due to activation of NMDA receptors. We repeated the experiments on a subset of five cells while applying $50 \mu \mathrm{M}$ D-AP5 as before. Under control conditions, the properties of the inputs are similar to the average of all the cells (Fig. 7A1-E1). Importantly, the NMDA component is evident from the nonlinear $I-V$ relation (Fig. 7C1, solid circles). After blocking NMDA receptors, the $I-V$ relations became linear (Fig. 7C2), as the NMDA conductance was suppressed (Fig. 7D2, thick blue line) while the AMPA/ kainate conductance was relatively unaffected (Fig. 7D1,D2, thick green lines). In the presence of D-AP5, the AMPA/kainate conductance completely accounted for the total excitatory conductance (Fig. 7D2, compare thick black and green lines). For comparison, the total excitatory conductance in the presence of D-AP5 (Fig. 7D2, thick black line) is overlaid on Figure 7D1 as the dotted black line. The waveform is identical to the AMPA/kainate component (Fig. 7D1, thick green line), indicating that the application of D-AP5 had little effect on the AMPA/kainate component, while completely suppressing the NMDA component (Fig. $7 D 2$, thick blue line). The absence of any discernible effect of NMDA receptor block on the AMPA/kainate component was similar to the results for the VS-GCs above.

Finally, similar to the VS-GCs, GABA block suppresses orientation selectivity of spiking in HS-GCs, and we wanted to determine the synaptic basis for this effect. The control responses in a subset of four cells were similar to the control for the larger group of cells (Fig. 8A1-E1), and show the characteristic nonlinear $I-V$ relation during preferred stimulation (Fig. 8C1), due to the presence of nonlinear NMDA receptors, along with linear AMPA/ kainate and inhibitory conductances (Fig. 8D1,E1). As before, in two cells we applied only $10 \mu \mathrm{M}$ SR95531 to block GABA recep- 


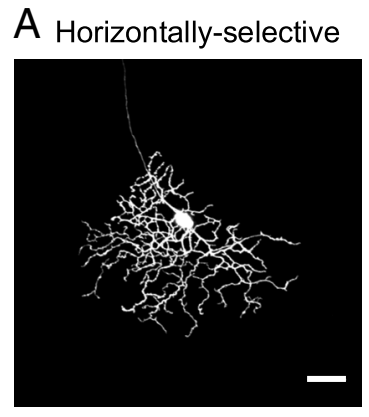

D

B Preferred

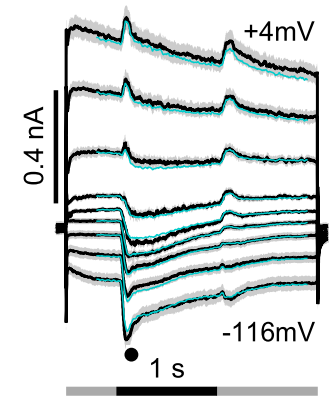

C Orthogonal

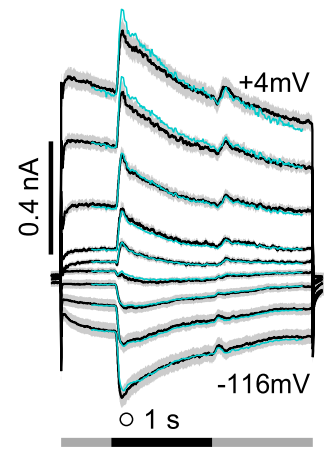

- Background

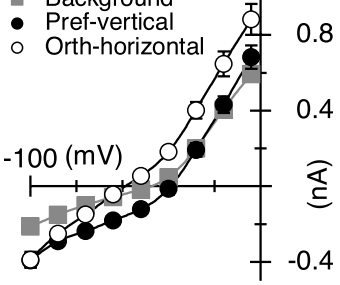

E
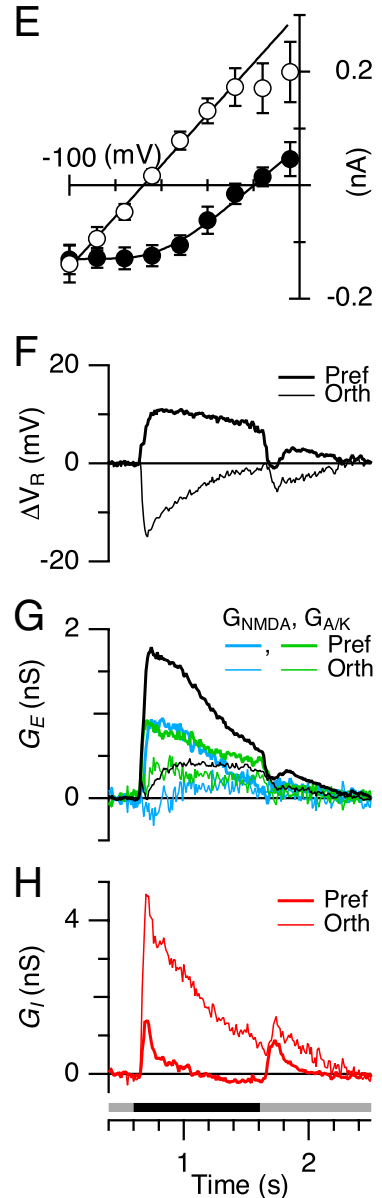

Figure 6. Ganglion cells selective for horizontally oriented stimuli. Marker and line conventions are identical to Figure 2. $A$, Dendritic morphology of a $\mathrm{HS}-\mathrm{GC}$ reconstructed from serial confocal micrographs. Scale bar, $50 \mu \mathrm{m} . \boldsymbol{B}, \boldsymbol{C}$, Average currents from 17 HS-GCs. D, Whole-cell current-voltage relations averaged from the cells used in $\boldsymbol{B}$ and $\boldsymbol{C}$. Error bars show the SEs for the group of cells, where they are larger than the symbols. $\boldsymbol{E}$, Net light-evoked component of the current obtained by subtracting the gray symbols from the open and solid symbols in $\boldsymbol{D}$. The solid lines show examples of the fitted lines that were used to derive the conductances. For the orthogonal data (open symbols), the most positive two data points were not included during fitting (see Materials and Methods). This omission results in a slight overestimation of the predicted currents at these potentials (cyan traces, $\boldsymbol{C}$. $\boldsymbol{F}$, Change in the whole-cell zerocurrent potential, $V_{R}$, as a function of time during the light stimulation. $\mathbf{G}$, Total excitatory conductance (black lines) is the sum of the nonlinear NMDA component (blue) and the linear AMPA/kainate component (green). These data were obtained by analyzing the average data shown in $\boldsymbol{B}$ and $\boldsymbol{C}$. $\boldsymbol{H}$, Inhibitory conductance activated during preferred (thick red) and orthogonal (thin red) stimulation.

tors, and in two additional cells we applied both $10 \mu \mathrm{M}$ SR95531 and $30 \mu \mathrm{M}$ TPMPA. Similar to the VS-GCs, the addition of TPMPA produced no obvious additional effect, and we combined the data. GABAergic block enhanced the total excitatory conductance, suppressed the direct inhibitory input, and strongly suppressed orientation selectivity (Fig. 8A2-E2). The AMPA/kai-

CONTROL

A1

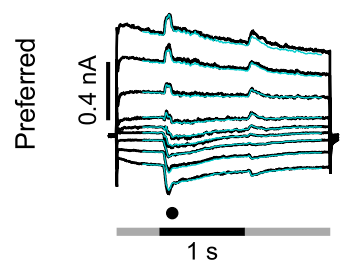

B1

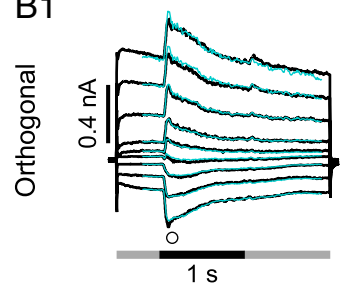

C1
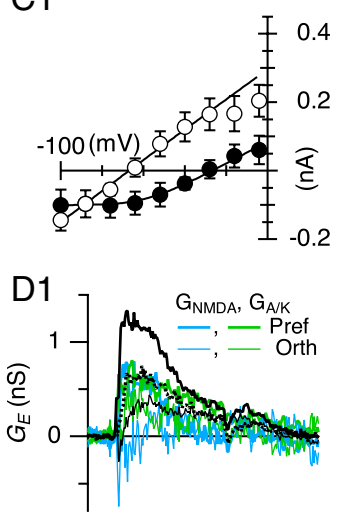

E1

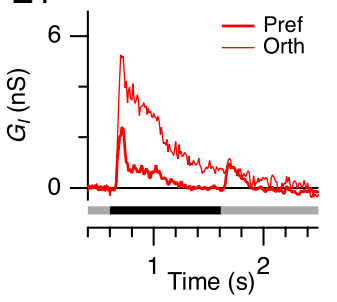

NMDA BLOCK

A2

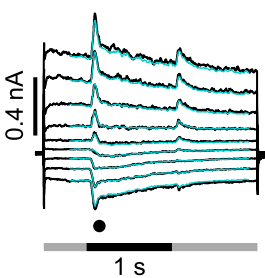

B2

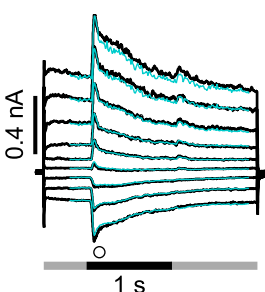

C2
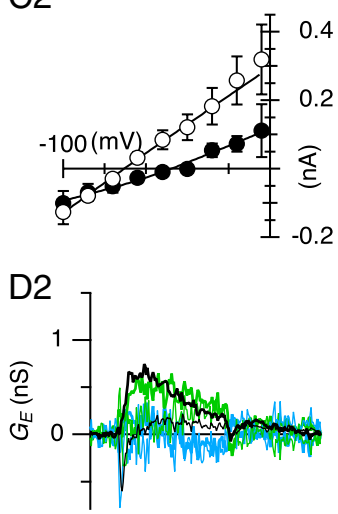

E2

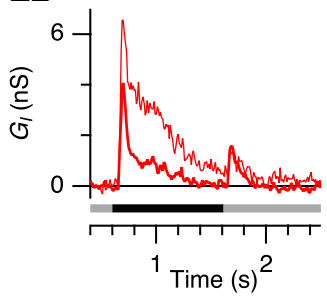

Figure 7. NMDA receptor antagonist blocks the nonlinear component in $\mathrm{HS}-\mathrm{GCS}$. The first column shows the control data (A1-E1), and the second column shows the effects of $50 \mu \mathrm{M}$ D-AP5 (A2-E2). Marker and line conventions are identical to Figure 2. $A, B$, Membrane currents averaged from five cells. $C$, Net light-evoked current-voltage relations obtained by subtraction as for Figure $2 E$. The NMDA antagonist completely suppressed the nonlinear component of the preferred $I-V$ relations. The most positive two data points were omitted during fitting of the orthogonal data in control. $\boldsymbol{D}, \boldsymbol{E}$, Net light-evoked synaptic conductances obtained by analyzing the data in $\boldsymbol{A}$ and $\boldsymbol{B}$. D-AP5 completely suppressed the NMDA input (thick blue line, D2) but did not affect the linear components (green lines) of the conductance. The dotted black line in D1, showing the total conductance in the presence of D-AP5, is replotted from D2.

nate component (Fig. 8D2, thick green line) during preferred stimulation is unaltered during GABAergic block while the increase in the excitatory conductance (Fig. 8D2, thick black line) can be accounted for by the increase in the NMDA inputs (Fig. $8 \mathrm{D} 2$, thick blue line). It is interesting to note that the opposite is true for the VS-GCs, i.e., during GABA block the AMPA/kainate component increased, while the NMDA component was unaffected (Fig. 4). GABAergic block also revealed a disinhibitory input (Fig. $8 \mathrm{E}$ ), but it is unclear whether this input is masked under control conditions, or whether it results from network effects of the GABA receptor antagonists. 
CONTROL
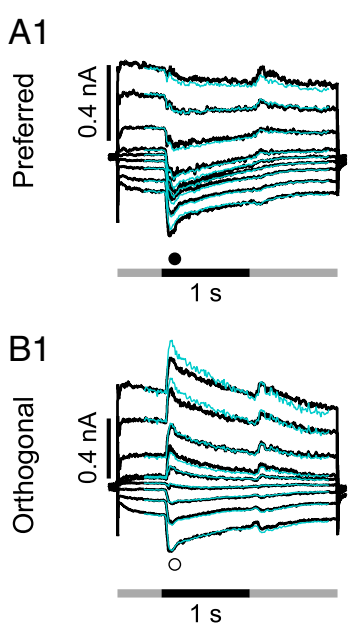

C1
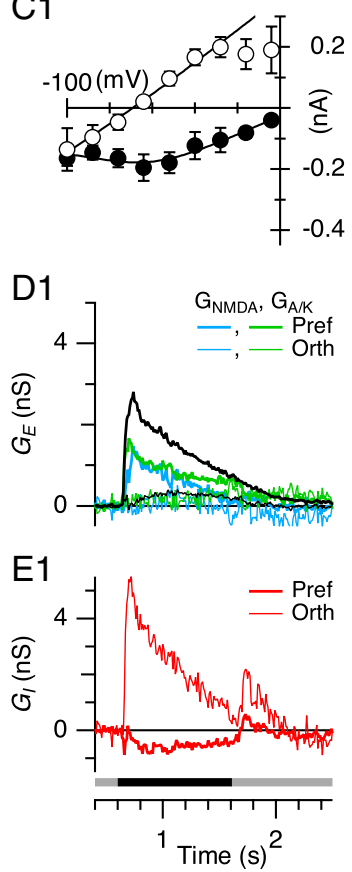

GABA BLOCK

A2

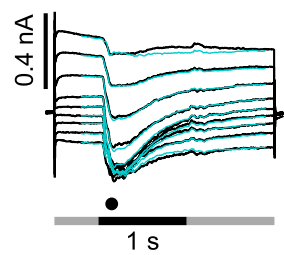

B2

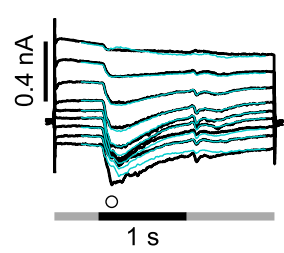

$\mathrm{C} 2$

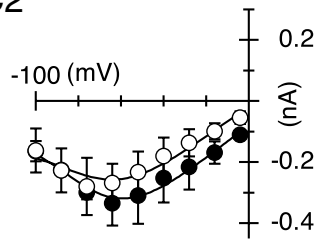

D2

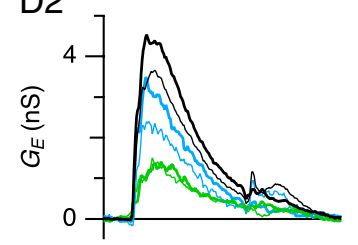

E2

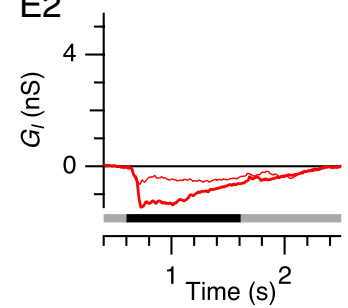

Figure 8. $G A B A_{A}$ and $G A B A_{C}$ receptor antagonists suppress orientation selectivity in $\mathrm{HS}-\mathrm{GCS}$. The first column shows the control data (A1-E1), and the second column shows the effects of coapplication of $10 \mu \mathrm{M}$ SR-95331 and $30 \mu \mathrm{M}$ TPMPA (A2-E2). Marker and line conventions are identical to Figure 2. $\boldsymbol{A}, \boldsymbol{B}$, Membrane currents averaged from four cells. $\boldsymbol{C}$, Net light-evoked current-voltage relations. The most positive two data points were omitted during fitting of the orthogonal data in control. $\boldsymbol{D}, \boldsymbol{E}$, Net light-evoked synaptic conductances. Blocking GABA receptors suppressed the light-evoked inhibitory inputs to the HS-GCs during orthogonal stimulation (compare $\boldsymbol{B} 1$ with $\boldsymbol{B} 2$ and $\boldsymbol{E} 1$ with $\mathbf{E 2}$ ), and enhanced excitation.

These results indicated that the inhibitory input to the HSGCs could be mediated by GABA receptors, but we wanted to test for the involvement of glycinergic transmission. Application of the glycinergic antagonist strychnine $(1 \mu \mathrm{M})$ to three cells also suppressed much of the inhibitory input to the HS-GCs (Fig. 9E2). The strychnine-sensitive inhibition was sustained. During orthogonal stimulation, strychnine blocked $\sim 80 \%$ of the integrated conductance between 0.7 and $1.65 \mathrm{~s}$ (Fig. 9E), while the initial transient at the onset of the stimulus, between 0.64 and $0.7 \mathrm{~s}$, was essentially unchanged (within $\sim 10 \%$ ). Similarly, the transient inhibition observed during preferred stimulation was insensitive to the strychnine (Fig. 9E, thick red line). These latter

CONTROL
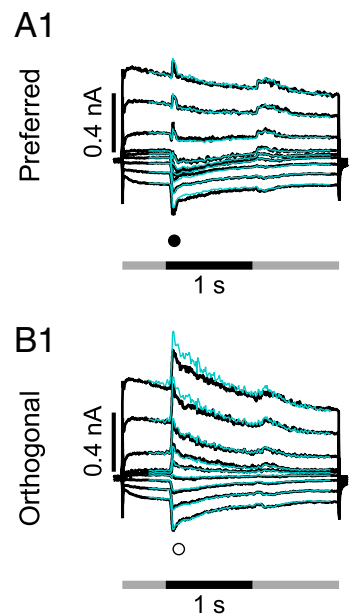

C1
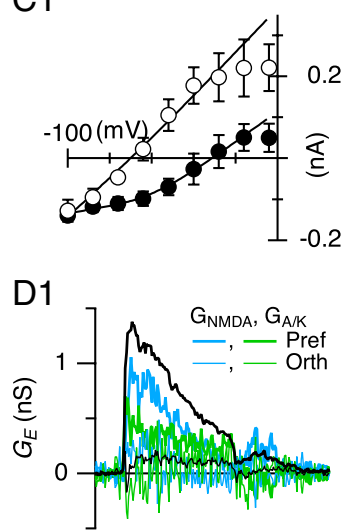

E1

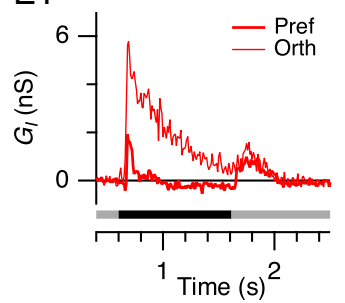

GLYCINE BLOCK

A2

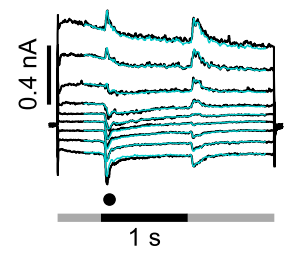

B2

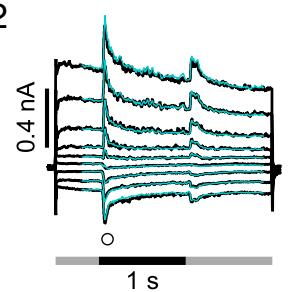

C2

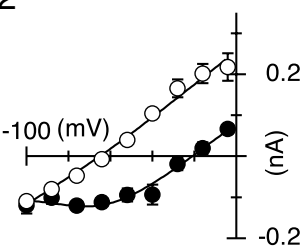

D2

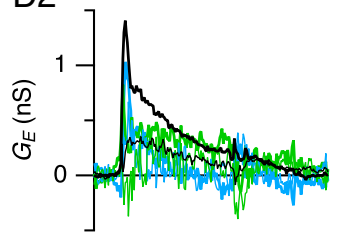

E2

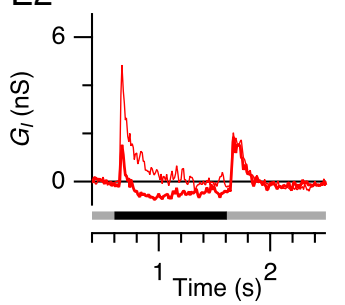

Figure 9. Glycine receptor antagonist suppresses sustained component of the inhibition in HS-GCS. Similar to the experiments for VS-GCS (Fig. 5), the background light intensity used here was $1 \log$ unit higher than usual. Contrast was 60\% (negative). The first column shows the control data $(A 1-E 1)$, and the second column shows the effects of application of $1 \mu \mathrm{m}$ strychnine (A2-E2) . A, B, Membrane currents averaged from three cells. C, Net light-evoked currentvoltage relations measured during horizontal and vertical stimulation. The most positive two data points were omitted during fitting of the orthogonal data in control. Blocking glycine receptors suppressed a sustained component of the light-evoked inhibitory inputs to the HSGCs during orthogonal stimulation (compare thin red lines, $\mathbf{E 1}$ and $\mathbf{E 2}$ ). The area under the traces between 0.7 and $1.65 \mathrm{~s}$ was reduced by $79 \%$ in the presence of strychnine. In contrast, the area under the initial transient phase of inhibition $(t=0.64-0.7 \mathrm{~s})$ was $\sim 13 \%$ larger in the presence of strychnine. The initial peak of the total excitatory conductance was unaffected by strychnine (thick black lines, D1, D2), although a sustained component was suppressed, due to suppression of the NMDA component of the excitation.

results indicate that strychnine did not act by simply blocking the rod pathway at the glycinergic connection from AII amacrine cells to OFF-cone bipolar cells (BCs) (Müller et al., 1988), in which case all synaptic drive to the cell should be equally suppressed. Therefore, the results with strychnine suggest that the HS-GCs receive a direct glycinergic input. The NMDA inputs 
also became more transient during glycine receptor block (Fig. $9 D$, thick blue trace).

The minimal circuitry required to explain these observations is explained in detail in the discussion. While the circuit focuses only on the OFF pathway inputs that these cells receive, it is clear from the spike data in Figure $1 A$ that the VS-GCs, in particular, receive some $\mathrm{ON}$ input (Fig. $1 A 1$, open triangles). To investigate the role of the $\mathrm{ON}$ input in orientation selectivity in these OFFGCs, we recorded currents from the cells as described above but flashed bright bars ( $60 \%$ positive contrast, $1 \mathrm{~mm}$ long, $100 \mu \mathrm{m}$ wide) in the preferred and orthogonal orientations. The results from four VS-GCs and four HS-GCs are shown in Figure 10. Bright bars of either orientation produced similar net lightevoked $I-V$ relations in VS-GCs (Fig. 10A1). The light-evoked response could be accounted for by a small, sustained suppression of excitatory input (Fig. $10 \mathrm{D1}$ ), and sustained inhibition (Fig. 10E1). The OFF response seen at the termination of the bright bar stimulus was largely identical to the response elicited by the onset of a dark bar (Fig. 2), albeit somewhat more transient (Fig. 10B-E1). Similarly, for HS-GCs the net light-evoked $I-V$ relations during the bright bar were not orientation selective (Fig. $10 A 2)$, but resulted from small increases in both excitation and inhibition (Fig. 10C-E2). Similar to the VS-GCs, the pattern of synaptic inputs at the termination of the bright bar (Fig. 10B-E2) were largely identical to the presentation of a dark bar (Fig. 6). The results indicate that the $\mathrm{ON}$ pathway provides some input to OS-GCs, although the input lacks any orientation specificity. Further studies would be required to evaluate the function, if any, of this $\mathrm{ON}$ input.

\section{Discussion}

In line with previous studies (Levick, 1967; Caldwell et al., 1978; Amthor et al., 1989; Bloomfield, 1994; He et al., 1998), we identified only two preferred orientations for ganglion cells in the rabbit retina-horizontal, which is parallel to the visual streak, and vertical. Moreover, in agreement with previous pharmacological studies (Caldwell et al., 1978), we found that GABAergic transmission was essential for generating orientation selectivity in both cell types, and we extended these findings by showing that GABAergic mechanisms rendered both excitatory and inhibitory inputs orientation selective. The spiking phenotypes of the two cell classes were very similar except for the preferred orientation, yet the underlying synaptic inputs displayed distinct differences.

\section{Proposed synaptic circuits}

In an effort to summarize the data and pinpoint differences in the synaptic circuitry for the discussion that follows, we constructed models of the orientation-selective circuitry for the two cell types. The guiding principle in generating these models was to use the minimum number of cells and synapses that could account for the observations. The simplest explanation for the excitatory drive is OFF-center-bipolar cells that synapse directly with the OS-GCs (Fig. 11 A, B, OFF-BC\#1). Both cell types displayed evidence for glutamatergic input via both non-NMDA (AMPA/kainate receptors) and NMDA receptors. Differential modulation of the NMDA and AMPA/kainate inputs during GABAergic block suggest that they arise either from distinct bipolar cell types or from different presynaptic terminals. Independent activation of NMDA receptors is plausible in this system, as they are synaptically localized in the OFF sublamina (Sagdullaev et al., 2006; Zhang and Diamond, 2009). However, the evidence for separate pathways is inconclusive, and therefore the proposed model
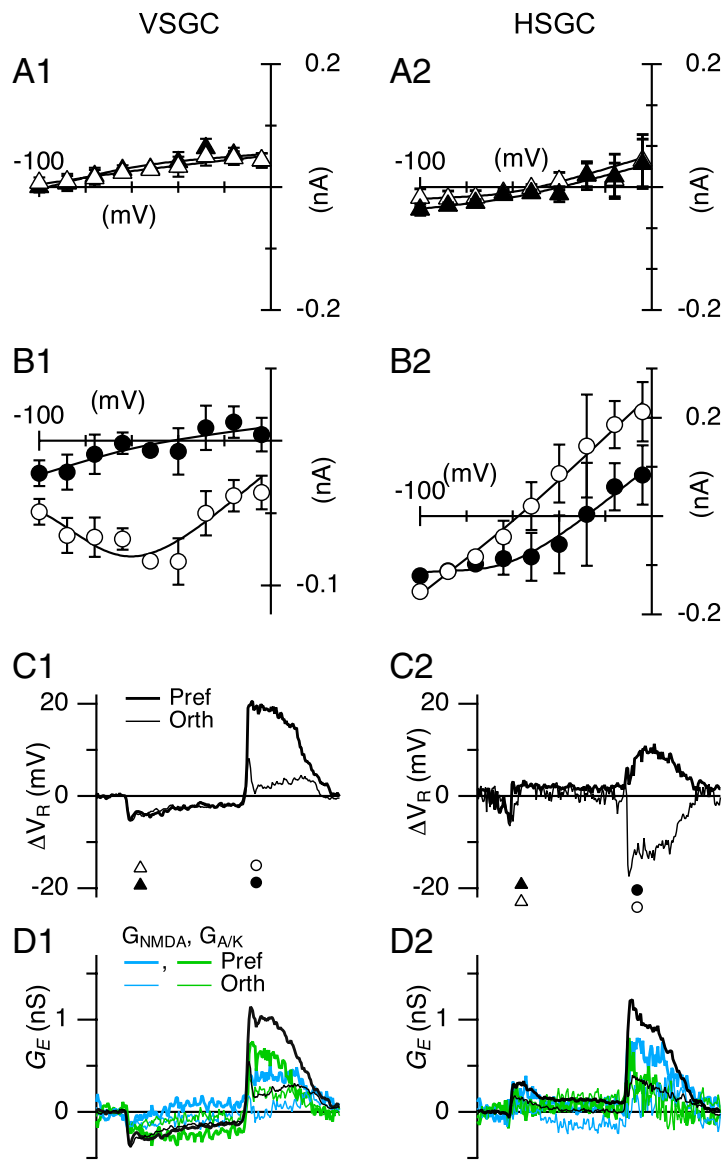

C2
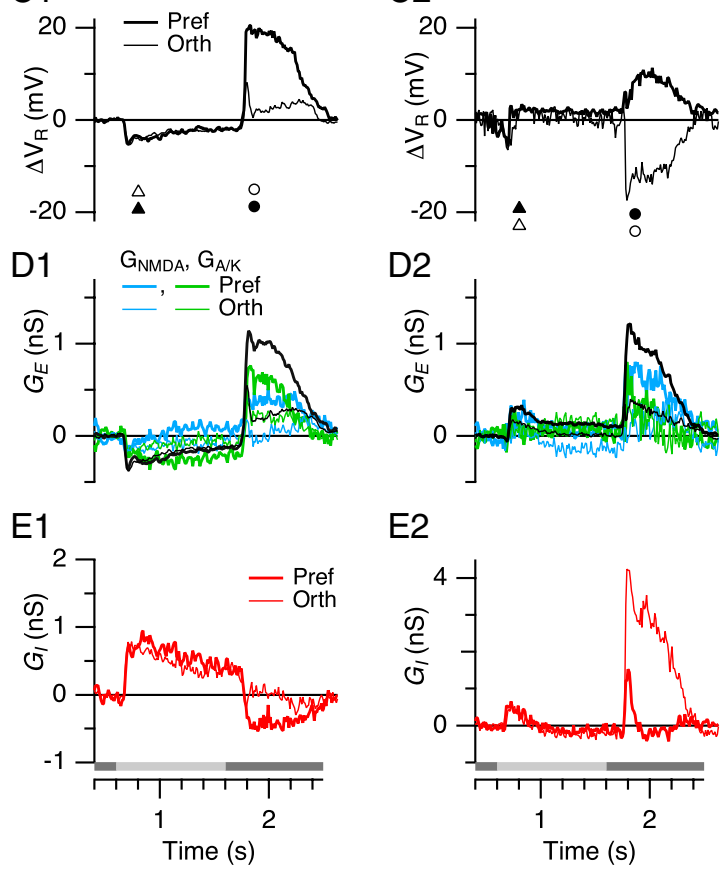

E2

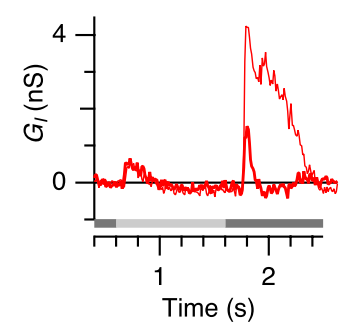

Figure 10. ON responses in VS-GCs and HS-GCS. Both cell types were stimulated with bright bars, $1 \mathrm{~mm}$ long and $100 \mu \mathrm{m}$ wide, flashed for $1 \mathrm{~s}$ in either the vertical or orthogonal orientation ( $60 \%$ positive contrast). $\boldsymbol{A}$, Net light-evoked $/-V$ relations for the $0 \mathrm{~N}$ response measured during preferred and orthogonal stimulation of VS-GCS $(n=4)$ and HS-GCS $(n=4$, time point indicated by triangles in $\boldsymbol{C}$. $\boldsymbol{B}$, Net light-evoked $/-V$ relations during the OFF response at the termination of the bright bar stimulus for preferred and orthogonal orientation (time point indicated by the circles shown in $\boldsymbol{C}$. $C$, Change in the whole-cell zero-current potential, $V_{R^{\prime}}$ as a function of time during the light stimulation. $\boldsymbol{D}$, Net excitatory conductance activated during preferred and orthogonal stimulation. $\boldsymbol{E}$, Inhibitory conductance activated during preferred and orthogonal stimulation.

shows the NMDA and non-NMDA inputs arising from a common bipolar cell type.

To account for the orthogonal suppression of excitation, we include wide-field, OFF-center amacrine cells that mediate orientation-selective inhibition of the OFF-bipolar cell axon terminals (Fig. 11A, B, OFF-AC\#1). Since the orientation selectivity of the excitatory inputs was blocked by GABA antagonists (Figs. 4,8 ), we propose that this presynaptic inhibition is GABAergic, most likely mediated by $\mathrm{GABA}_{\mathrm{A}}$ receptors. Note that the model is not proposing that this GABAergic amacrine cell is itself necessarily orientation selective, only that the connections with the 

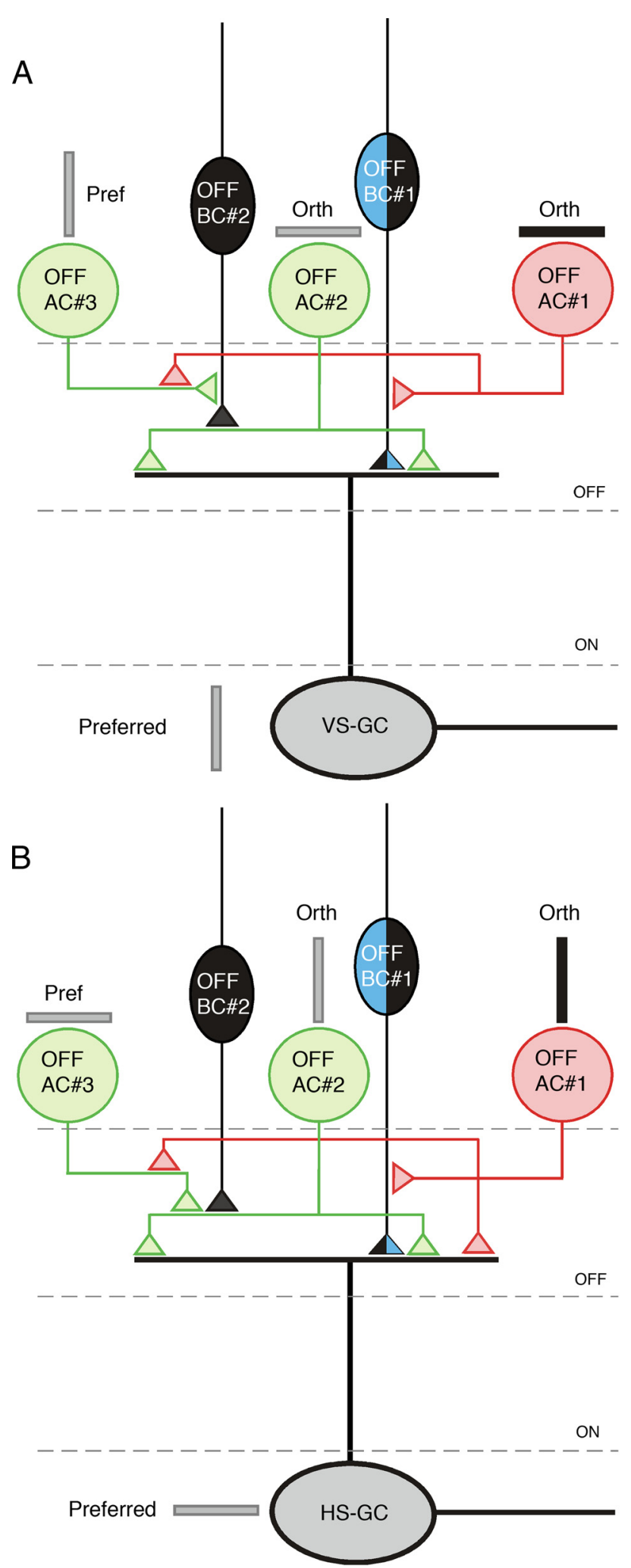

Glycine GABA AMPA/Kainate NMDA

Figure 11. Proposed synaptic circuit. The transmitter released by the cells is denoted by the color of the shading, and the legend at the bottom. In the case of the bipolar cells, which release glutamate, the shading indicates that the cells drive diverse postsynaptic receptors. The horizontal and vertical bars denote the preferred orientation for the responses of the various cells. A gray bar indicates that the orientation selectivity is generated by virtue of synaptic inputs, and a black bar indicate that orientation selectivity originates with the synaptic connections from the GABAergic amacrine cell (AC\#1). Note that AC\#1 itself is not necessarily 0S; for example, bipolar cell terminals are orientation selective. This could arise, for example, from a spatial asymmetry between the GABAergic amacrine cells the bipolar cells. The model does not explicitly account for quantitative details of the suppression of the excitation; for example, the AMPA/kainate inputs tended to be less orientation selective than the NMDA inputs (Figs. 2, 6G).

Unlike the HS-GCs, the VS-GCs received additional excitatory drive mediated by disinhibition, which was only present during preferred stimulation (Fig. $2 \mathrm{H}$ ). Disinhibition requires a tonically active inhibitory input, here provided by AC\#2 (Fig. $11 A$ ). The amplitude of the disinhibition was enhanced during GABAergic block (Fig. 4E), and completely suppressed by glycinergic block (Fig. $5 E$ ), implying that it is mediated by a glycinergic amacrine cell. Since this disinhibition is not orientation selective during GABA block, we include another glycinergic amacrine cell (OFF-AC\#3) to produce the disinhibition. Disinhibition is rendered OS, and GABA-blocker sensitive, by having OFF-AC\#3 receive input from the same GABAergic inputs that suppress the excitation (OFF-AC\#1).

A major difference between the VS-GCs and the HS-GCs was that the latter received direct inhibition that was larger during orthogonal stimulation. Unlike the VS-GCs, these direct inhibitory inputs to the HS-GCs were blocked by GABAergic blockers (Fig. 8E), which might be compatible with a direct GABAergic input, however, a sustained component of this direct inhibition was also suppressed by blocking glycine receptors (Fig. 9E). The simplest scheme that can explain these two results is identical to that for the vertical cells, except that OFF-AC\#3 inhibits OFFAC\#2 rather than the bipolar cell input to OFF-AC\#2 (Fig. $11 B$ ). During preferred stimulation, the outputs from OFF-AC\#1 are inactive, and OFF-AC\#3 prevents activation of OFF-AC\#2. Conversely, during orthogonal stimulation, OFF-AC\#1 suppresses OFF-AC\#3, which allows OFF-AC\#2 to provide a sustained, strychnine sensitive inhibitory input to the HS-GC. During GABAergic block all orientations result in suppression of OFFAC\#2 by OFF-AC\#3. Thus, the proposed model accounts for the result that either glycinergic blockers or GABAergic blockers suppress sustained direct inhibitory input to the HS-GCs. Finally, there is a transient inhibitory component that is not orientation selective. Since this inhibitory component was strychnine resistant and was activated at both the onset and termination of a stimulus, it is likely mediated by direct GABAergic inputs to the HS-GCs from an ON-OFF amacrine cell. We have not included this component in the model.

In both cases, the glycinergic ACs that directly inhibit the OS-GCs are gated by another glycinergic AC, which feeds forward in the HS-GC circuit but feeds back onto bipolar cells in the VS-GC circuit. The notion that there are serial inhibitory networks in the retina is well supported by previous physiological and anatomical studies (Dowling and Boycott, 1966; Vaughn et al., 1981; Zhang et al., 1997; Eggers and Lukasiewicz, 2006; Eggers and Lukasiewicz, 2010). A notable feature of the VS-GC model was the presence of excitation mediated via glycinergic disinhibi-

$\leftarrow$

orientation selectivity could be generated by spatial asymmetries in the connections between this cell and the other cells. $\boldsymbol{A}$, To produce the disinhibition observed, AC\#2 is proposed to be tonically active, while AC\#1 and AC\#3 produce sustained signals. $B$, The inhibitory feedforward connection from $A C \# 1$ is transient, but the feedback to $A C \# 3$ should be more sustained to account for the sustained, orientation-selective inhibition observed. For simplicity, a single cell is shown, but in reality more than one cell type would be required, one sustained and the other transient. The model ignores the sustained ON inhibition observed in the VS-GCS, which is not orientation selective. 
tion. OFF- $\alpha$-ganglion cells also receive excitatory drive mediated in part by glycinergic disinhibition originating from the $\mathrm{ON}$ pathway via AII amacrine cells (Manookin et al., 2008; van Wyk et al., 2009). Our data do not allow us to decide whether the orientation-selective disinhibition observed here also arises from such cross-over inhibition. While it is possible to construct a model for the VS-GCs that includes cross-over inhibition from the ON pathway, the OFF-pathway model presented above is simpler, and the close similarity to the HS-GC model is appealing.

\section{A role for NMDA receptors}

NMDA receptors are distributed throughout the inner plexiform layer (IPL) (Fletcher et al., 2000; Zhang and Diamond, 2009), and are colocalized with AMPA/kainate receptors (Mittman et al., 1990; Diamond and Copenhagen, 1993). The synaptic localization differs between the ON and OFF sublaminae of the IPL. In the outer layers (OFF sublaminae), NR2A-containing heteromeric channels are localized within the synapses, while within the inner layers (ON sublaminae), NR2B receptors are perisynaptic (Zhang and Diamond, 2009). These differences in synaptic localization appear to be paralleled by differences in the presynaptic inhibition (Sagdullaev et al., 2006). The results presented here predict that NMDA receptors comprise a significant fraction of the excitatory current driving depolarization, even at potentials close to the expected resting potential of the cell. Moreover, the orientation sensitivity of the NMDA component tended to be stronger than for the AMPA/kainate component, indicating that NMDA inputs represent an important component of OS circuitry in both VS-GCs and HS-GCs. A similar analysis of NMDA inputs to ganglion cells in the guinea pig retina indicates that NMDA receptors contribute to contrast sensitivity in OFF $\alpha$-cells (Manookin et al., 2010).

\section{Comparison with previous studies}

While there have been reports of ON-center (Bloomfield, 1994) and ON-OFF (Amthor et al., 1989) OS-GCs, we only rarely encountered ON-center OS-GCs in our initial recordings, but it is possible that we undersampled this class, since we subsequently focused on finding the OFF-center units. On the other hand, our data accord well with previous studies that also encountered a preponderance of OFF-center OS-GCs in rabbit (Levick, 1967; Caldwell et al., 1978). Since Levick's original characterization (Levick, 1967), the morphologies of only five OS-GCs have been published. The morphologies shown in Figures $2 A$ and $5 A$ and supplemental Figure S1 (available at www.jneurosci.org as supplemental material) are comparable with previous examples (Amthor et al., 1989; Bloomfield, 1994). The uniform physiological responses suggest that the OFF-center OS-GCs described here most likely represent distinct functional classes. Future work will be required to establish whether receptive fields of each type tile the retina without gaps, and thus generate complete representations of the visual space optimized for the orientation of edges.

Our data are consistent with the notion that orientation selectivity is due to asymmetries in the arrangement of the inhibitory receptive field (Levick, 1967; Caldwell et al., 1978). In this context, anomalies in the spatial properties are interesting. For example, extended orthogonal bars completely suppress spiking (Fig. 1E), whereas large spot stimuli, which cover a larger total area, appear to elicit less inhibition in that they fail to completely suppress spiking (Fig. 1D). Moreover, the space constants for inhibition obtained from the extended bars are not consistent with the space constants obtained for surround inhibition from spot stimuli. Together, these findings suggest that there may be inhibitory interactions between the surrounding inhibitory mechanisms.

The results indicate that the excitatory inputs to OS-GCs from bipolar cells are themselves orientation selective. Similarly, the ON-OFF DSGCs and ON-DSGCs, of which there are seven populations, each with a distinct preferred direction, receive directional excitatory inputs (Euler et al., 2002; Fried et al., 2002, 2005; Taylor and Vaney, 2002). Thus, the imposition of a "trigger feature," like orientation or direction selectivity, on the output from bipolar cells appears to be a common feature of retinal circuitry. This is perhaps unexpected, because there are fewer distinct morphological classes of bipolar cell than ganglion cell, not to mention the many diverse populations of amacrine cells, all of which must receive bipolar cell input. The challenge for future research is to determine how a relatively limited number of bipolar cell types can be multiplexed to provide such selective inputs to all the different classes of ganglion and amacrine cells.

\section{References}

Ames A 3rd, Nesbett FB (1981) In vitro retina as an experimental model of the central nervous system. J Neurochem 37:867-877.

Amthor FR, Takahashi ES, Oyster CW (1989) Morphologies of rabbit retinal ganglion cells with complex receptive fields. J Comp Neurol 280:97-121.

Ascher P, Nowak L (1988) The role of divalent cations in the N-methyl-Daspartate responses of mouse central neurones in culture. J Physiol 399:247-266.

Binzegger T, Douglas RJ, Martin KA (2004) A quantitative map of the circuit of cat primary visual cortex. J Neurosci 24:8441-8453.

Bishop PO, Coombs JS, Henry GH (1971) Interaction effects of visual contours on the discharge frequency of simple striate neurones. J Physiol 219:659-687.

Bloomfield SA (1994) Orientation-sensitive amacrine and ganglion cells in the rabbit retina. J Neurophysiol 71:1672-1691.

Bruno RM, Sakmann B (2006) Cortex is driven by weak but synchronously active thalamocortical synapses. Science 312:1622-1627.

Caldwell JH, Daw NW, Wyatt HJ (1978) Effects of picrotoxin and strychnine on rabbit retinal ganglion cells: lateral interactions for cells with more complex receptive fields. J Physiol 276:277-298.

Chapman B, Zahs KR, Stryker MP (1991) Relation of cortical cell orientation selectivity to alignment of receptive fields of the geniculocortical afferents that arborize within a single orientation column in ferret visual cortex. J Neurosci 11:1347-1358.

Diamond JS, Copenhagen DR (1993) The contribution of NMDA and nonNMDA receptors to the light-evoked input-output characteristics of retinal ganglion cells. Neuron 11:725-738.

Dowling JE, Boycott BB (1966) Organization of the primate retina: electron microscopy. Proc R Soc Lond B Biol Sci 166:80-111.

Dunn FA, Doan T, Sampath AP, Rieke F (2006) Controlling the gain of rod-mediated signals in the mammalian retina. J Neurosci 26:3959-3970.

Eggers ED, Lukasiewicz PD (2006) GABA(A), GABA(C) and glycine receptor-mediated inhibition differentially affects light-evoked signalling from mouse retinal rod bipolar cells. J Physiol 572:215-225.

Eggers ED, Lukasiewicz PD (2010) Interneuron circuits tune inhibition in retinal bipolar cells. J Neurophysiol 103:25-37.

Euler T, Detwiler PB, Denk W (2002) Directionally selective calcium signals in dendrites of starburst amacrine cells. Nature 418:845-852.

Ferster D, Miller KD (2000) Neural mechanisms of orientation selectivity in the visual cortex. Annu Rev Neurosci 23:441-471.

Fletcher EL, Hack I, Brandstätter JH, Wässle H (2000) Synaptic localization of NMDA receptor subunits in the rat retina. J Comp Neurol 420:98-112.

Fried SI, Münch TA, Werblin FS (2002) Mechanisms and circuitry underlying directional selectivity in the retina. Nature 420:411-414.

Fried SI, Münch TA, Werblin FS (2005) Directional selectivity is formed at multiple levels by laterally offset inhibition in the rabbit retina. Neuron 46:117-127.

He S, Levick WR, Vaney DI (1998) Distinguishing direction selectivity from orientation selectivity in the rabbit retina. Vis Neurosci 15:439-447. 
Hubel DH, Wiesel TN (1962) Receptive fields, binocular interaction and functional architecture in the cats' visual cortex. J Physiol 160:106-154.

Kim I-J, Zhang Y, Yamagata M, Meister M, Sanes JR (2008) Molecular identification of a retinal cell type that responds to upward motion. Nature 452:478-482.

Levick WR (1967) Receptive fields and trigger features of ganglion cells in the visual streak of the rabbits retina. J Physiol 188:285-307.

Manookin MB, Beaudoin DL, Ernst ZR, Flagel LJ, Demb JB (2008) Disinhibition combines with excitation to extend the operating range of the OFF visual pathway in daylight. J Neurosci 28:4136-4150.

Manookin MB, Weick M, Stafford BK, Demb JB (2010) NMDA receptor contributions to visual contrast coding. Neuron 67:280-293.

Mittman S, Taylor WR, Copenhagen DR (1990) Concomitant activation of two types of glutamate receptor mediates excitation of salamander retinal ganglion cells. J Physiol 428:175-197.

Morrone MC, Burr DC, Maffei L (1982) Functional implications of crossorientation inhibition of cortical visual cells. I. Neurophysiological evidence. Proc R Soc Lond B Biol Sci 216:335-354.

Müller F, Wässle H, Voigt T (1988) Pharmacological modulation of the rod pathway in the cat retina. J Neurophysiol 59:1657-1672.

Priebe NJ, Ferster D (2008) Inhibition, spike threshold, and stimulus selectivity in primary visual cortex. Neuron 57:482-497.

Reid RC, Alonso JM (1995) Specificity of monosynaptic connections from thalamus to visual cortex. Nature 378:281-284.

Roska B, Molnar A, Werblin FS (2006) Parallel processing in retinal ganglion cells: how integration of space-time patterns of excitation and inhibition form the spiking output. J Neurophysiol 95:3810-3822.

Sagdullaev BT, McCall MA, Lukasiewicz PD (2006) Presynaptic inhibition modulates spillover, creating distinct dynamic response ranges of sensory output. Neuron 50:923-935.

Sasaki YF, Rothe T, Premkumar LS, Das S, Cui J, Talantova MV, Wong HK, Gong X, Chan SF, Zhang D, Nakanishi N, Sucher NJ, Lipton SA (2002) Characterization and comparison of the NR3A subunit of the NMDA receptor in recombinant systems and primary cortical neurons. J Neurophysiol 87:2052-2063.

Sillito AM, Kemp JA, Milson JA, Berardi N (1980) A re-evaluation of the mechanisms underlying simple cell orientation selectivity. Brain Res 194:517-520.

Stepanyants A, Hirsch JA, Martinez LM, Kisvárday ZF, Ferecskó AS, Chklovskii DB (2008) Local potential connectivity in cat primary visual cortex. Cereb Cortex 18:13-28.

Tanaka K (1983) Cross-correlation analysis of geniculostriate neuronal relationships in cats. J Neurophysiol 49:1303-1318.

Taylor WR, Vaney DI (2002) Diverse synaptic mechanisms generate direction selectivity in the rabbit retina. J Neurosci 22:7712-7720.

Tong G, Takahashi H, Tu S, Shin Y, Talantova M, Zago W, Xia P, Nie Z, Goetz T, Zhang D, Lipton SA, Nakanishi N (2008) Modulation of NMDA receptor properties and synaptic transmission by the NR3A subunit in mouse hippocampal and cerebrocortical neurons. J Neurophysiol 99:122-132.

van Wyk M, Wässle H, Taylor WR (2009) Receptive field properties of ONand OFF-ganglion cells in the mouse retina. Vis Neurosci 26:297-308.

Vaughn JE, Famiglietti EV Jr, Barber RP, Saito K, Roberts E, Ribak CE (1981) GABAergic amacrine cells in rat retina: immunocytochemical identification and synaptic connectivity. J Comp Neurol 197:113-127.

Vidyasagar TR, Heide W (1984) Geniculate orientation biases seen with moving sine wave gratings: implications for a model of simple cell afferent connectivity. Exp Brain Res 57:176-200.

Wilent WB, Contreras D (2005) Dynamics of excitation and inhibition underlying stimulus selectivity in rat somatosensory cortex. Nat Neurosci 8:1364-1370.

Woodhull AM (1973) Ionic blockage of sodium channels in nerve. J Gen Physiol 61:687-708.

Zhang J, Diamond JS (2009) Subunit- and pathway-specific localization of NMDA receptors and scaffolding proteins at ganglion cell synapses in rat retina. J Neurosci 29:4274-4286.

Zhang J, Jung CS, Slaughter MM (1997) Serial inhibitory synapses in retina. Vis Neurosci 14:553-563. 